\title{
Ultimate Compressive Strength of Stiffened Panel: An Empirical Formulation for Flat-Bar Type
}

\author{
Do Kyun Kim ${ }^{1,2} \mathbb{D}$, Su Young Yu ${ }^{1}$, Hui Ling Lim ${ }^{3}$ and Nak-Kyun Cho ${ }^{4, *}$ \\ 1 Group of Marine, Offshore and Subsea Technology (MOST), School of Engineering, Newcastle University, \\ Newcastle upon Tyne NE1 7RU, UK; do.kim@ncl.ac.uk (D.K.K.); sy.yu@ncl.ac.uk (S.Y.Y.) \\ 2 Graduate Institute of Ferrous Technology (GIFT), Pohang University of Science and Technology (POSTECH), \\ Pohang 37673, Korea \\ 3 Ocean and Ship Technology (OST) Research Group, Department of Civil and Environmental Engineering, \\ PETRONAS University of Technology (UTP), Seri Iskandar, Perak 32610, Malaysia; do.kim@postech.ac.kr \\ 4 Department of Manufacturing Systems and Design Engineering, Seoul National University of Science and \\ Technology (SeoulTech), Seoul 01811, Korea \\ * Correspondence: nkcho@seoultech.ac.kr
}

Received: 31 July 2020; Accepted: 6 August 2020; Published: 13 August 2020

\begin{abstract}
This research aims to study the ultimate limit state (ULS) behaviour of stiffened panel under longitudinal compression by a non-linear finite element method (NLFEM). There are different types of stiffeners mainly being used in shipbuilding, i.e., T-bar, flat-bar, and angle-bar. However, this research focuses on the ultimate compressive strength behaviour of flat-bar stiffened panel. A total of 420 reliable scenarios of flat-bar stiffened panel were selected for numerical simulation by the ANSYS NLFEM. The ultimate strength behaviours obtained were used as data for the development of closed form shape empirical formulation. Recently, our group proposed an advanced empirical formulation for T-bar stiffened panel, and the applicability of the proposed formulation to flat-bar stiffened panel is confirmed by this study. The accuracy of the empirical formulation obtained for flat-bar stiffened panel was validated by finite element (FE) simulation results of statistical analysis $\left(R^{2}=0.9435\right)$. The outcome obtained will be useful for ship structural designers in predicting the ultimate strength performance of flat-bar type stiffened panel under longitudinal compression.
\end{abstract}

Keywords: ocean and shore technology (OST); empirical formula; ultimate limit state; longitudinal compression; stiffened plate; ships and offshore structures; structural design

\section{Introduction}

It is common for stiffened and unstiffened panels to be used for primary structural supporting members in the field of ocean and shore technology (OST), including shipping and offshore industries. In general, mild (MS24) and high tensile (AH32 or AH 36) steel grades are being used as construction materials for voyages in the Southern Sea Route (SSR). In the case of the Northern Sea Route (NSR), which was opened due to the global warming effect, the different grades of the steels, i.e., B, D, E, or F, are recommended to be used [1-3].

A wide range of studies in assessing and predicting the structural condition of intact and damaged structures have been conducted by many researchers for the robust design of ships and offshore structures. In particular, the finite element method (FEM), one of the famous numerical methods, is considered a powerful technique for solving issues in various fields, such as engineering and medical. Moreover, the computational fluid dynamics (CFD)-based and fluid-structure interaction (FSI)-based numerical simulations are also getting more and more popular in structural design, following the development of computer technology [4]. 
The experimental and analytical methods, meanwhile, are also considered useful ways to resolve engineering issues, provided that there is adequate financial support and time frame given, subject to physical limitation, such as equipment size and testing area issues. In the case of analytical methods, while it provides an absolute solution, it has the limitation of not covering complex geometries with actual environmental conditions [5].

In this regard, the design formulation or the empirical formulation approach is studied [6] and adopted by major classification societies, such as Lloyd's Register (LR), the American Bureau of Shipping (ABS), and Det Norske Veritas Germanischer Lloyd (DNV GL), and followed by major shipyards in general. A number of empirical formulations and simplified techniques were proposed by various researchers in terms of ultimate limit state of intact and damaged hull girders [7-14], unstiffened panel (plate) [15-17], stiffened panel [6,18-22], and many others.

Recently, historical and technical reviews on existing empirical formulations in predicting the ultimate limit state (ULS) have been conducted for unstiffened and stiffened panels [23,24]. In the case of stiffened panel, which is made of steel and aluminium, most of the existing empirical formulations $[6,21,25-30]$ were developed as a function of two parameters. such as plate slenderness ratio $\beta$ and column slenderness ratio ( $\lambda$ ), by adopting the plate stiffener combination (PSC) model.

More recently, Kim et al. [21] addressed that ultimate compressive strength of stiffened panel tends to fluctuate in the lower range of the column of slenderness ratio $(\lambda)$ as shown in Figure 1. This means that stiffened panel has a higher nonlinearity with the combination of plate and stiffener geometries. Therefore, simplified or single line shape empirical formulation, such as a function of $\beta$ and $\lambda$, may not be accurate in representing the ultimate strength behaviour of stiffened panel. Moreover, additional parameters should be considered in predicting the accurate ultimate compressive strength behaviour of stiffened panel.

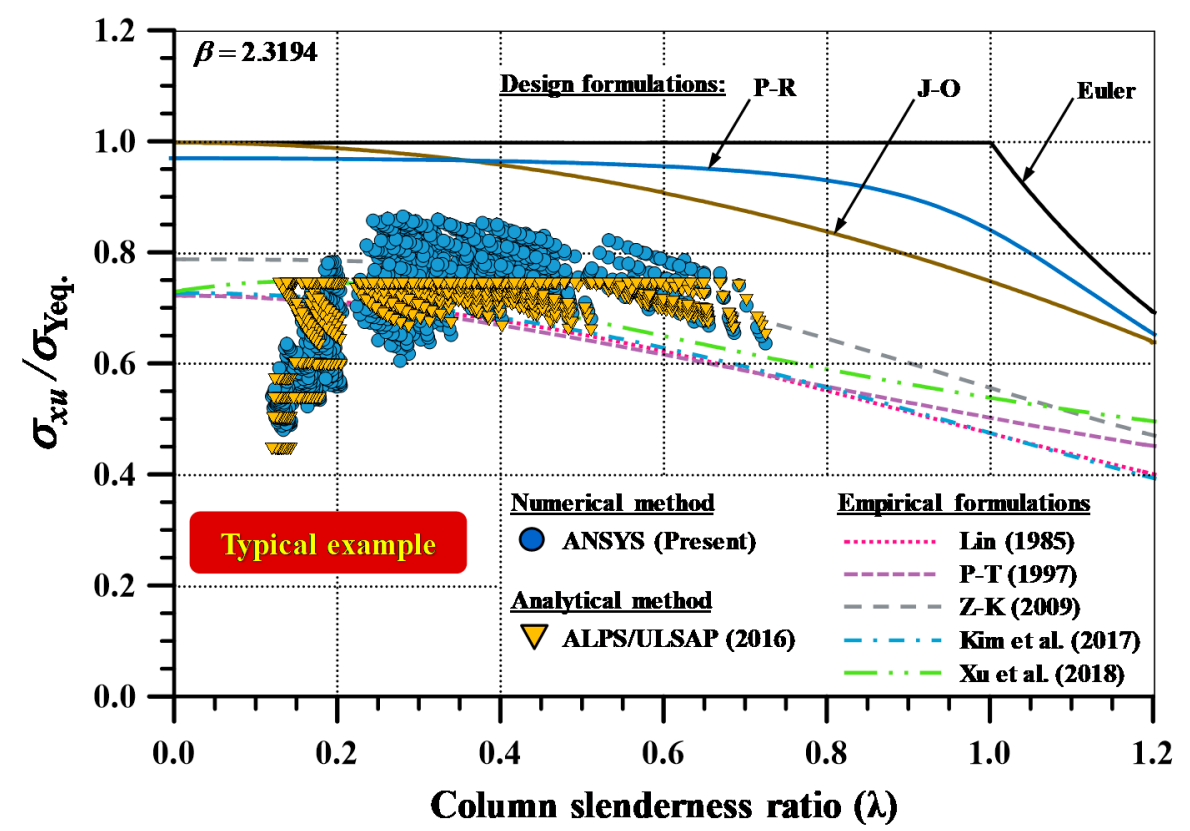

Figure 1. Typical example of the existing design and empirical formulations in predicting the ultimate limit state (ULS) of T-bar stiffened panel [24]. (Note: The permission of reproduction for this figure is given by Elsevier).

In this regard, Kim et al. [6] introduced a refined empirical formulation in predicting the ultimate compressive strength of T-bar type stiffened panel, as shown in Figure 2, by using a conventional data processing technique with four (4) parameters, such as plate slenderness ratio $(\beta)$, column slenderness ratio $(\lambda)$, web slenderness ratio $\left(h_{w} / t_{w}\right)$, and moment of inertia of stiffener to moment of inertia of plate ratio in z-direction (vertical) $\left(I_{s z} / I_{p z}\right)$ From the wide range of numerical simulations (in total 
10,500 scenarios of T-bar stiffened panel), an advanced empirical formulation by data processing technique has been proposed [6] with reliable accuracy of ULS, compared by ANSYS FE numerical simulation results $\left(\mathrm{R}^{2}=0.98\right)$. Details may be referred to Kim et al. [6].

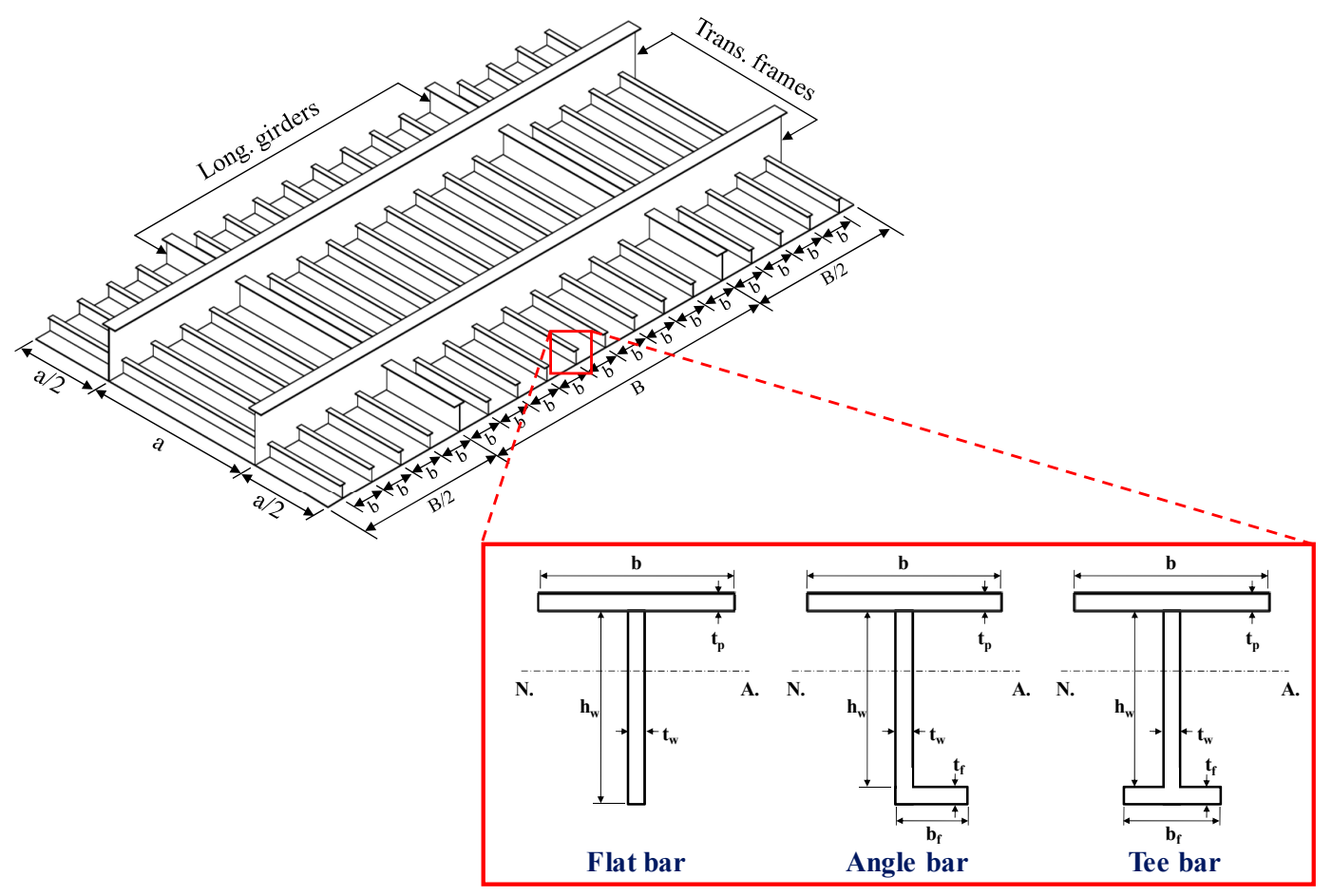

Figure 2. Schematic view of the stiffened panel with three types of stiffeners. (Note: $a=$ plate length; $B=$ breadth of stiffened panel (one span); $b=$ plate breadth; $t_{p}=$ plate thickness; $h_{w}=$ web height; $t_{w}=$ web thickness; $b_{f}=$ flange breadth; $t_{f}=$ flange thickness; N.A. = neutral axis.)

Most of the existing empirical formulations can be used in predicting the ULS of T-bar stiffened panel under longitudinal compression. However, there are limited studies conducted on flat- and angle-bar stiffened panel. In this regard, 540 numerical simulations were conducted by the ANSYS non-linear finite element method (NLFEM) to obtain the ultimate strength of flat-bar type stiffened panel under longitudinal compression. The ULS results of flat-bar stiffened panel were utilised as the input for the data processing. In addition, the applicability of the empirical formulation proposed by Kim et al. [6] was also tested as to whether it can be fitted for flat-bar or otherwise.

Finally, the accuracy of the refined empirical formulation for flat-bar stiffened panel obtained in this study was verified by statistical analysis. The applicability of the outcome obtained from this study was verified by ANSYS FE numerical simulations, as well as existing empirical formulations for flat-bar stiffened panel, by adopting single line shape formulations [21,25,26,28,29].

A useful outcome was achieved in predicting the ULS of flat-bar stiffened panel, which is one of the primary structural components of ships and offshore structures.

\section{Brief Review of the Existing Formulations}

As mentioned earlier, recently Zhang [23] and Kim et al. [24] provided detailed technical reviews on existing design and empirical formulations to predict the ultimate strength of the stiffened panel. The details of the same can be found in the articles mentioned above.

In this study, the representative existing empirical formulations are addressed in this section. The formulations introduced in this paper are used for comparison with FE numerical simulation by statistical analysis in the following section. In general, the empirical formulations in predicting the 
ultimate limit state (ULS) of the stiffened panel formulates as a function of plate slenderness ratio $(\beta)$ and column slenderness ratio $(\lambda)$, as shown in Equation (1).

$$
\sigma_{x u} / \sigma_{Y e q .}=f(\beta, \lambda)
$$

where $\sigma_{x u}$ is the ultimate compressive strength in $x$-axis (under longitudinal compression), $\sigma_{Y e q \text {. }}$ is the equivalent yield strength of plate and stiffener, $\beta$ is the plate slenderness ratio $\left(=\left(b_{p} / t_{p}\right) \cdot \sqrt{\left(\sigma_{Y p} / E\right)}\right)$, $\lambda$ is the column slenderness ratio $\left(=[L /(\pi \cdot r)] \cdot \sqrt{\left(\sigma_{Y e q .} / E\right)}\right), \sigma_{Y p}=$ is the yield strength of plate, $E$ is the Young's modulus, $L$ is the length of the stiffened panel, $r$ is the radius of gyration $(=\sqrt{(I / A)})$, and $I$ and $A$ are the moment of inertia and sectional area for the plate-stiffener combination (PSC) model's section, respectively.

By assuming the basic format of empirical formulations, illustrated in Equation (1), a number of empirical formulations (or closed form shape formulations) were proposed by experimental and numerical methods. The common design formulations used in a shipyard are presented in Equations $(2 a-c)$. Details on existing design formulations can be found in the research by Paik [16].

Euler formulation

$$
\sigma_{E} / \sigma_{\text {Yeq. }}=\left\{\begin{array}{lll}
1.0 & \text { for } & \lambda \leq 1.0 \\
1 / \lambda^{2} & \text { for } & \lambda>1.0
\end{array}\right.
$$

Johnson-Ostenfeld ( $\mathrm{J}-\mathrm{O})$ formulation

$$
\sigma_{c r} / \sigma_{Y e q .}=\left\{\begin{array}{ccc}
1 / \lambda^{2} & \text { for } & \sigma_{E} / \sigma_{Y e q .} \leq 0.5 \\
1-\lambda^{2} / 4 & \text { for } & \sigma_{E} / \sigma_{Y e q .}>0.5
\end{array}\right.
$$

Perry-Robertson (P-R) formulation under axial compression

$$
\sigma_{x u} / \sigma_{\text {Yeq. }}=\frac{1}{2}\left(1+\frac{1+\eta}{\lambda^{2}}\right)-\sqrt{\frac{1}{4}\left(1+\frac{1+\eta}{\lambda^{2}}\right)^{2}-\frac{1}{\lambda^{2}}}
$$

Lin [25] also suggested the generalised shape of the empirical formulation to predict the ultimate strength of the stiffened panel subject to longitudinal compression, as shown in Equation (3a). Thereafter, Paik and Thayamballi [26] proposed the revised empirical formulation, based on the test database collected. In addition, they set the upper limit of the empirical formulation, of which the ultimate compressive strength of stiffened panel may not exceed the elastic buckling stress $\left(\sigma_{\text {Yeq. }} / \lambda^{2}\right)$, as shown in Equation (3b). The coefficients consisting of Equation $(3 a, b)$ are summarised in Table 1.

Table 1. Coefficients to predict ULS.

\begin{tabular}{ccc}
\hline Coefficient & Lin [26] & P-T $^{*}[26]$ \\
\hline$C_{1}$ & 0.960 & 0.995 \\
$C_{2}$ & 0.765 & 0.936 \\
$C_{3}$ & 0.176 & 0.170 \\
$C_{4}$ & 0.131 & 0.188 \\
$C_{5}$ & 1.046 & -0.067 \\
\hline \multicolumn{3}{c}{ * Paik and Thayamballi (P-T). }
\end{tabular}

General shape of the empirical formulation

$$
\sigma_{x u} / \sigma_{Y e q .}=\frac{1}{\sqrt{c_{1}+c_{2} \lambda^{2}+c_{3} \beta^{2}+c_{4} \lambda^{2} \beta^{2}+c_{5} \lambda^{4}}}
$$

where $c_{1}-c_{5}$ are the coefficients, which can be found in Table 1 . 
Upper limit of empirical formulation

$$
\sigma_{x u} / \sigma_{Y e q .}=\frac{1}{\sqrt{c_{1}+c_{2} \lambda^{2}+c_{3} \beta^{2}+c_{4} \lambda^{2} \beta^{2}+c_{5} \lambda^{4}}} \leq \frac{1}{\lambda^{2}}
$$

More recent empirical formulations are also summarised in Equations (4)-(6). Zhang and Khan [28] proposed Equation (4) with a limitation of the range of column slenderness ratio $(\lambda \leq \sqrt{2})$. Kim et al. [21] also suggested that empirical formulation should be based on numerical simulations, which allows to cover the wide range of the column slenderness ratio. Recently, $\mathrm{Xu}$ et al. [29] proposed empirical formulation to predict the ULS of all types of stiffened panel, i.e., T-bar, angle-bar, and flat-bar subject to longitudinal compression, as well as lateral pressure. Among others, the empirical formulation for flat bar applied in this study is only presented in Equation (6).

Z-K formulation [28]

$$
\sigma_{x u} / \sigma_{Y e q .}=\frac{1}{\beta^{0.28} \sqrt{1.0+\lambda^{3.2}}} \quad \text { for } \lambda \leq \sqrt{2} \text { range only }
$$

Kim's formulation [21]

$$
\sigma_{x u} / \sigma_{Y e q .}=\frac{1}{0.8884+e^{\lambda^{2}}}+\frac{1}{0.4121+e \sqrt{\beta}}
$$

$X u^{\prime}$ s formulation [29] for flat bar

$$
\sigma_{x u} / \sigma_{\text {Yeq. }}=\frac{1}{\sqrt{\left(\begin{array}{c}
1.127-4.915 \lambda+0.49 \beta+0.773 \lambda \beta+10.075 \lambda^{2}-0.109 \beta^{2} \\
-0.14 \lambda^{2} \beta^{2}-7.089 \lambda^{3}+0.04 \beta^{3}+0.01 \lambda^{3} \beta^{3}+1.564 \lambda^{4}
\end{array}\right)}} \leq \frac{1}{\lambda^{2}}
$$

Details of existing empirical formulations and their technical reviews can be found in the research by Zhang [23] and Kim et al. [24]. It is highlighted that the existing empirical formulations in Equations (2)-(6) are presented as a single line shape equation, and this is one of the important reasons why advanced empirical formulation is required for predicting more accurate ULS results.

Recently, Mei and Wang [31] also proposed single line shape empirical formulation in predicting ULS of stiffened panel, which is a similar shape that proposed by Lin [25] and Paik-Thayamballi [26]. However, they limited the maximum order of plate and column slenderness ratios as second and third, respectively. The obtained FE results were limited to propose empirical formulation, so the outcome was not compared in this study.

Lastly, the common structural rule (CSR) method proposed by International Association of Classification Societies (IACS) [32] may also be considered as industrial standard for practical purposes. In April 2006, CSR for oil tankers [33] and bulk carriers [34] was proposed. With regards to design rule and methodology, detailed comparison with historical summaries was documented by Jiameng et al. [35] and Kim et al. [21]. Therefore, it will not be discussed further here.

\section{Ultimate Strength Calculations by the Non-Linear Finite Element Method (NLFEM)}

Limit state design (LSD), also known as load and resistance factor design (LRFD), is now a well-known design method in the field of structural engineering. The LSD [16] includes ultimate limit state (ULS), fatigue limit state (FLS), accidental limit state (ALS), and serviceability limit state (SLS). Among others, a number of studies have been conducted on ULS-based design, technique, and its applications in terms of ULS application to stiffened panels [36-39], scaling effect [40,41], stiffened panels with opening [42], dynamic ULS [43], low temperature effect [14], and prediction of ULS by an artificial neural network (ANN) [44]. The FLS of an offshore riser by an ANN and simplified 
method [45,46], the ALS and ULS of a non-ice class aged ship [4,47], a steel plated structure [3], a ship's hull [2], and Floating Liquefied Natural Gas (FLNG) [48,49] are also investigated.

\subsection{Selection of Scenarios of Flat-Bar Stiffened Panel}

Recently, Kim et al. [24] conducted a wide range of technical reviews on existing empirical formulation in predicting the ultimate strength of stiffened panel subject to longitudinal compression. In addition, they tested the accuracy of the existing empirical formulations by conducting 10,500 cases of T-bar stiffened panel numerical simulations using ANSYS NLFEM. The total number of stiffened panel scenarios were selected, as shown in Equation (7).

$$
\underset{a}{1} \times \underset{b}{1} \times \underset{t_{p}}{7} \times \underset{h_{w}}{10} \times \underset{t_{w}}{6} \times \underset{b_{f}}{5} \times \underset{t_{f}}{5}=10,500 \text { scenarios }
$$

where $a$ is the plate length, $b$ is the plate breadth, $t_{p}$ is the plate thickness, $h_{w}$ is the web height, $t_{w}$ is the web thickness, is the flange breadth, and $t_{f}$ is the flange thickness.

In this study, the flat-bar stiffened panel, which consisted of plate and web, was targeted, which meant that flat-bar stiffened panel did not have flange. In this regard, the 10,500 scenarios, as mentioned above in Equation (7), could be reduced to 420 cases by neglecting the flange part $\left(b_{f}\right.$ and $\left.t_{f}\right)$, so the scenarios of flange breadth $\left(b_{f}\right)$ and flange thickness $\left(t_{f}\right)$ could be not considered in this study. More details of the 420 scenarios, including material and geometric properties, can found in Equation (8) and Table 2.

$$
\underset{a}{1} \times \underset{b}{1} \times \underset{t_{p}}{7} \times \underset{h_{w}}{10} \times \underset{t_{w}}{6}=420 \text { scenarios }
$$

Table 2. (a) Material and geometric properties of selected flat-bar stiffened panels. * Plate stiffener combination (PSC). (b) Summary of selected scenarios.

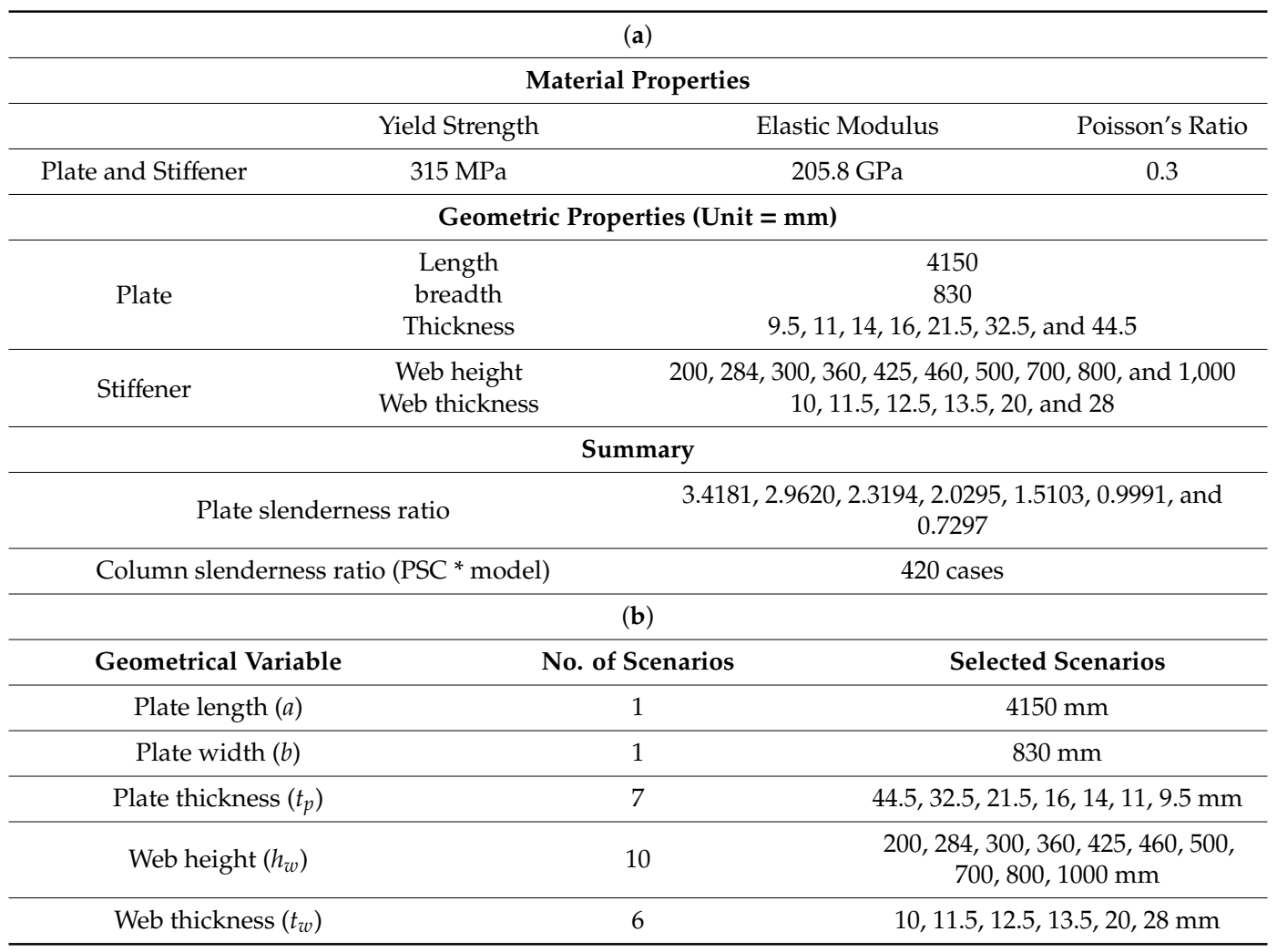


Table 2. Cont.

\section{Total number of scenarios}

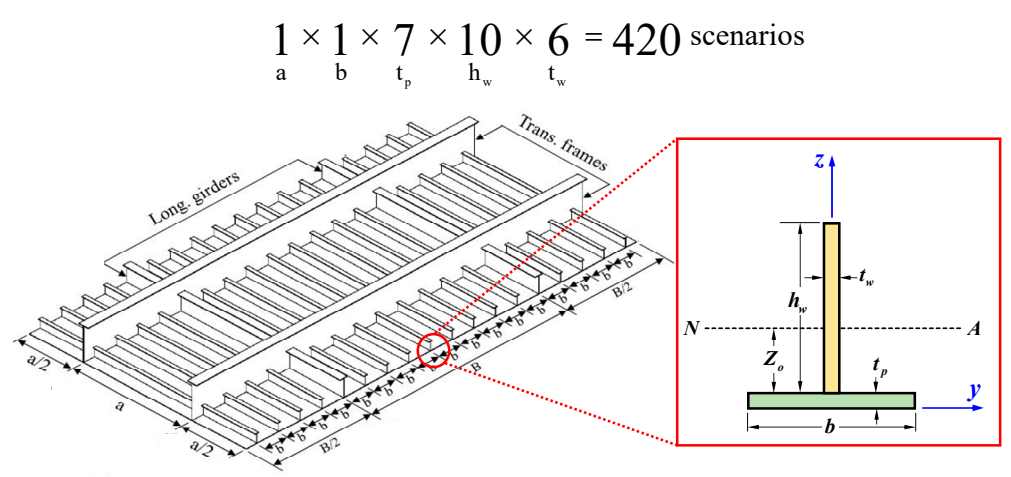

\subsection{Structural Modelling}

It is recognised that ultimate strength behaviour of stiffened and unstiffened panels varies depending on structural modelling technique, which means that the application of the appropriate FE structural modelling technique is essentially required in order to obtain realistic outcomes. In particular, the effect of assumed boundary condition, model size in longitudinal and transverse directions, material modelling technique, mesh size, initial imperfections, such as initial deflection and welding-induced residual stress, and many other elements should be carefully taken into consideration [50].

International Ship and Offshore Structures Congress (ISSC) [7] conducted a wide range of parametric studies on ultimate strength of stiffened panel by considering the changes of geometries. They studied the effect of model size on ULS by selecting one bay/one span and two bay/two span (1/2-1-1/2 model) stiffened panel models, as shown in Figure $3 a, b$. The details of boundary conditions for both models shown in Figure $3 a, b$ are summarised in Table $3 a, b$, respectively. As expected, the one bay/one span model resulted in the overestimation of the ULS value, rather than the two bay/two span model. This was due to the effect of sideways deformation of the stiffeners located at the transverse frames, which were not allowed for the one bay/one span model. This was also caused by the effect of boundary condition assumed in both models. The imperfection sensitivity and geometric effects in stiffened panel was also studied by Ahmer Wadee and Farsi [51].

Based on the findings by ISSC [7], the two bay/two span model, as shown in Figure $3 b$ and Table $3 b$ was adopted in this study with the average level of initial deflection for plate and initial distortions for stiffeners. Details on initial deflection can be found in the Appendix A. The welding-induced residual stress effect was not considered in this study. It was reported that 10-13\% decrement of ULS of stiffened panel is expected to be achieved due to the effect of welding-induced residual stress [52]. The number of mesh in plate and web part is 10 and 6, respectively, based on mesh convergence studies [7,21].

With regards to structural modelling technique, some recent studies can be referred to in terms of scaling effect and [40,41] geometric evaluation [53]. In the case of element type, the Shell181 element with four nodes and six degrees of freedom per node were adopted. In addition, the classical metal plasticity model in the ANSYS material library was used in this study. The applied material model was based on von Mises yield criterion to define isotropic yielding and isotropic hardening behaviour. In the present study, the bilinear type material curve with no tangential slope (no hardening effect) was adopted. For example, the yield stress will not change as plastic strain increased.

ISSC [54] also reported the effect of hardening on the ultimate strength of structures. The hardening behaviour appears only after material yields, when the stiffened panel undergoes large deformations and plastic strains appear. However, a bilinear curve with no hardening may help to secure the additional safety margin. Based on this, ISSC [7] also adopted a bilinear shape material curve, which consists of the combination of material elastic modulus and yield strength. 


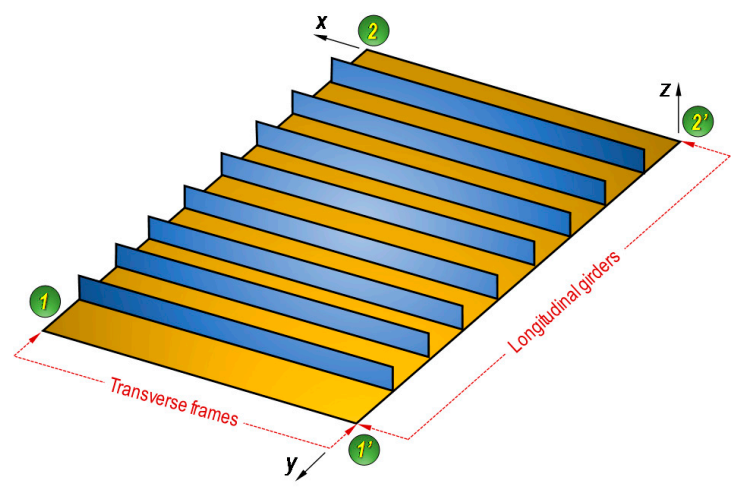

(a) one bay/one span model

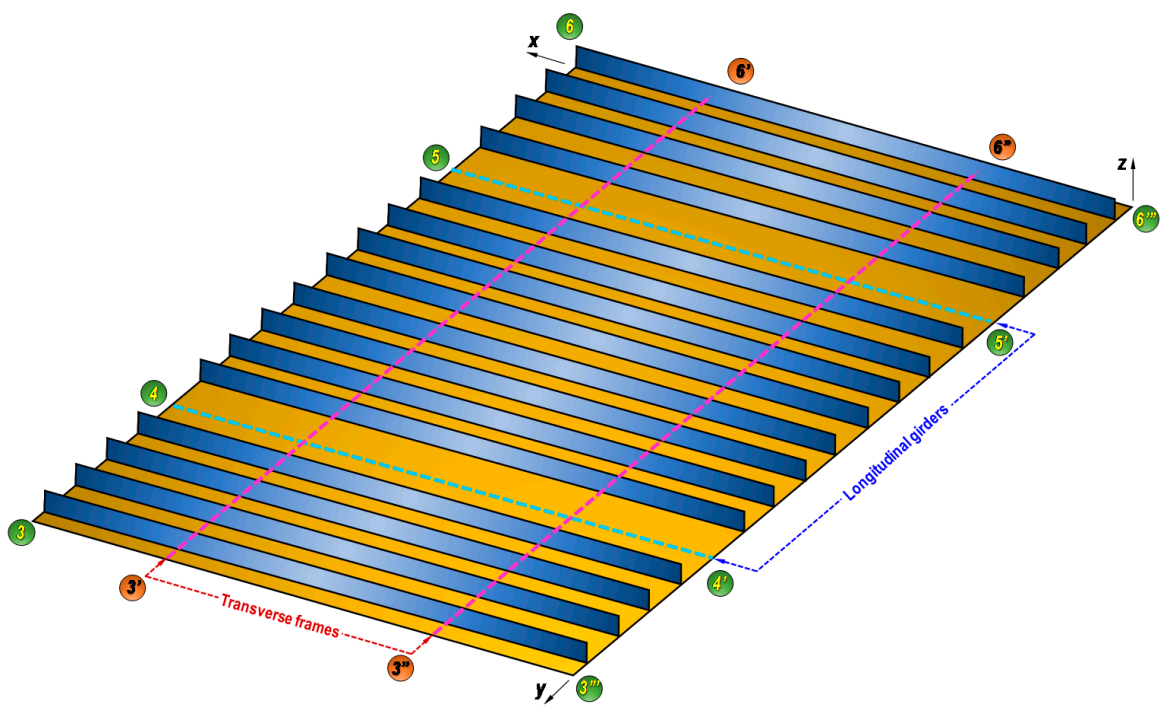

(b) two bay/two span model

Figure 3. Modelling of stiffened panel [7].

Table 3. Applied boundary condition [7].

(a) One Bay/One Span Model Found in Figure 3a

- Simply supported condition with

- $\quad \operatorname{Rot}_{\mathrm{y}}=\operatorname{Rot}_{\mathrm{z}}=0$ and $\mathrm{U}_{\mathrm{z}}=0$ (Fix)

$1-1^{\prime}$ and $2-2^{\prime}$

- Uniform displacement in the $y$-direction $\left(\mathrm{U}_{\mathrm{y}}=\right.$ uniform) coupled with the plate

- Simply supported condition with

$1-2$ and $1^{\prime}-2^{\prime}$

- $\operatorname{Rot}_{\mathrm{x}}=\operatorname{Rot}_{\mathrm{z}}=0$ and $\mathrm{U}_{\mathrm{z}}=0$ (Fix)

- Uniform displacement in the $\mathrm{x}$-direction $\left(\mathrm{U}_{\mathrm{x}}=\right.$ uniform) coupled with the longitudinal stiffeners

(b) Two Bay/Two Span Model Found in Figure 3b

\begin{tabular}{|c|c|}
\hline $3-3^{\prime \prime \prime}$ and $6-6^{\prime \prime \prime}$ & $\begin{array}{l}\text { - Symmetric condition with } \operatorname{Rot}_{\mathrm{x}}=\operatorname{Rot}_{\mathrm{y}}=0 \text { (Fix) } \\
\text { - Uniform displacement in the y-direction }\left(\mathrm{U}_{\mathrm{y}}=\text { uniform) coupled }\right. \\
\text { with the plate }\end{array}$ \\
\hline $3-6$ and $3^{\prime \prime \prime}-6^{\prime \prime \prime}$ & $\begin{array}{l}\text { - Symmetric condition with } \mathrm{R}_{\mathrm{y}}=\mathrm{R}_{\mathrm{z}}=0(\mathrm{Fix}) \\
\text { - Uniform displacement in the } \mathrm{x} \text {-direction }\left(\mathrm{U}_{\mathrm{x}}=\text { uniform) coupled }\right. \\
\text { with the longitudinal stiffener }\end{array}$ \\
\hline $3^{\prime}-6^{\prime}, 3^{\prime \prime}-6^{\prime \prime}, 4-4^{\prime}$, and $5-5^{\prime}$ & - $\mathrm{U}_{\mathrm{z}}=0$ (Fix) \\
\hline
\end{tabular}


For the FE simulation, the arc-length method was employed in conjunction with the modified Newton Raphson method in standard and modified forms, which enabled us to obtain an accurate load-shortening curve. In addition, all simulations were conducted based on the above method, with a large displacement option in the ANSYS NLFEM. The above FE simulation setting may be capable and was recommended for implementing buckling analysis of the complex structural shape.

\subsection{Structural Analysis and Results}

Prior to conducting numerical simulation, the results of FE technique validation with ISSC [7] is shown in Figure 4a. A total of 420 numerical simulations by ANSYS were conducted to obtain ULS of flat-bar stiffened panel under longitudinal compression. As shown in Figure $4 \mathrm{~b}$, the ULS trends were plotted based on $\lambda$ and $\beta$. As expected, ULS tended to decrease when the $\lambda$ increased. When the plate slenderness ratio increased or the plate was getting thinner, the ULS tended to maintain a general trend. This is $t$ discussed further in the following section, in comparison with empirical formulation.

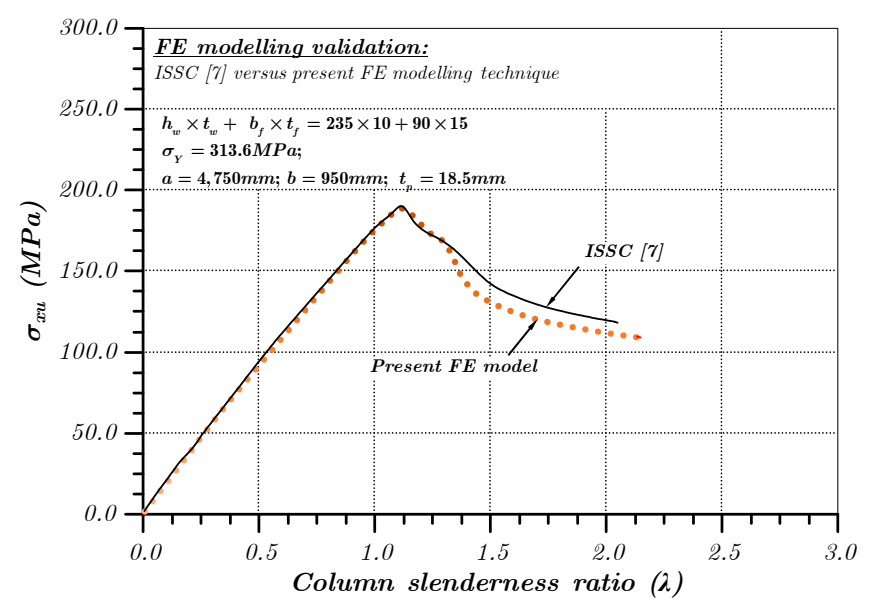

(a)

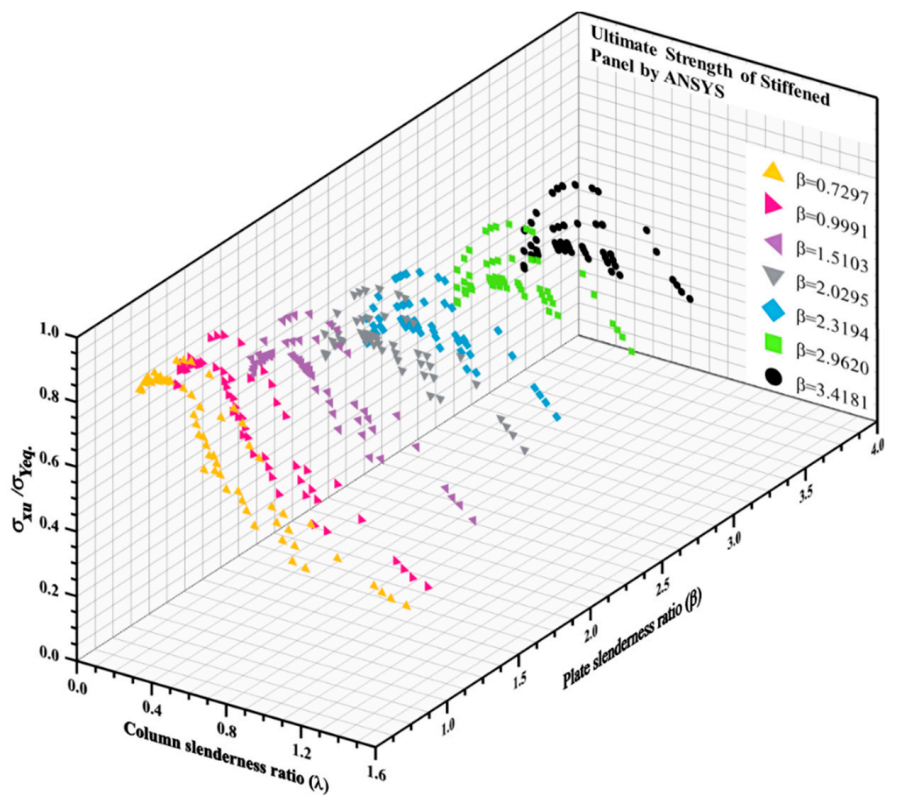

(b)

Figure 4. The calculated ULS results by the ANSYS nonlinear finite element method. (a) FE modelling validation [24] (Note: The permission of reproduction for this figure is given by Elsevier.) (b) All scenarios. 


\section{Development of Empirical Formulation and Verification of its Applicability}

\subsection{Empirical Formulation for Flat-Bar Stiffened Panel}

Recently, an advanced empirical formulation was conducted by Kim et al. [6] to predict the ultimate strength of the T-bar type stiffened panel under longitudinal compression. A wide range of the numerical simulations of 10,500 cases in total were conducted by considering the changes of the geometric properties in terms of plate and stiffener.

This confirmed that the fluctuation behaviour of the ULS was found in the small range of the column slenderness ratio, as illustrated in Figure 1. In order to predict the ULS of stiffened panel more accurately, Kim et al. [6] additionally considered two important parameters, i.e., web slenderness ratio, $h_{w} / t_{w}$, and moment of inertia of stiffener to moment of inertia of plate ratio in z-direction, $I_{p z} / I_{s z}=\left(h_{w} t_{w}^{3}+t_{f} b_{f}^{3}\right) /\left(t_{p} b^{3}\right)$, in addition to the two original basic parameters, i.e., $\beta$ and $\lambda$, as shown in Equation (1).

The numerical simulation results obtained were analysed by a data processing technique, and the polynomial function shape empirical formulation [6] is presented in Equation (9). By adopting the proposed empirical formulation, 15 coefficients for flat-bar were newly obtained based on FE numerical simulation in this study. Table 4 shows the 15 coefficients for T-bar and flat-bar, consisting of the empirical formulations. The data processing procedure proposed by Kim et al. [6] is shown in Figure 5 .

$$
\sigma_{x u} / \sigma_{Y e q}=\left[\begin{array}{rr}
c_{0}+\left(c_{1}+c_{2} \sqrt{\lambda}+\frac{c_{3}}{\beta}+c_{4} \frac{h_{w}}{t_{w}}+c_{5} \sqrt{\frac{I_{p z}}{I_{s z}}}\right) \sqrt{\lambda}+\left(c_{6}+\frac{c_{7}}{\beta}+c_{8} \frac{h_{w w}}{t_{w w}}+c_{9} \sqrt{\frac{I_{p z}}{I_{s z}}}\right) \frac{1}{\beta} \\
+\left(c_{10}+c_{11} \frac{h_{w v}}{t_{w}}+c_{12} \sqrt{\frac{I_{p z}}{I_{s z}}}\right) \frac{h_{w w}}{t_{w w}} & +\left(c_{13}+c_{14} \sqrt{\frac{I_{p z}}{I_{s z}}}\right) \sqrt{\frac{I_{p z}}{I_{s z}}}
\end{array}\right] \leq 1.0
$$

Table 4. Coefficients for empirical formulations to predict the ULS of stiffened panel.

\begin{tabular}{ccc}
\hline & \multicolumn{2}{c}{ Coefficients } \\
\cline { 2 - 3 } Terms & T-Bar [6] & Flat-Bar (Present) \\
\cline { 2 - 3 }$C_{0}$ & -0.1449 & -1.5721 \\
$C_{1}$ & 2.9787 & 5.6591 \\
$C_{2}$ & -2.6098 & -3.7336 \\
$C_{3}$ & -0.2418 & -0.6934 \\
$C_{4}$ & $1.2374 \times 10^{-3}$ & $-1.8581 \times 10^{-2}$ \\
$C_{5}$ & $1.3470 \times 10^{-2}$ & $1.7858 \times 10^{-2}$ \\
$C_{6}$ & 0.8841 & 1.3546 \\
$C_{7}$ & -0.3361 & -0.3482 \\
$C_{8}$ & $1.5975 \times 10^{-3}$ & $-1.9443 \times 10^{-3}$ \\
$C_{9}$ & $2.7745 \times 10^{-3}$ & $0.8850 \times 10^{-3}$ \\
$C_{10}$ & $-7.5919 \times 10^{-3}$ & $1.8299 \times 10^{-2}$ \\
$C_{11}$ & $3.2442 \times 10^{-5}$ & $-1.2316 \times 10^{-4}$ \\
$C_{12}$ & $4.9670 \times 10^{-5}$ & $1.4994 \times 10^{-4}$ \\
$C_{13}$ & $1.3267 \times 10^{-2}$ & $-1.8752 \times 10^{-4}$ \\
$C_{14}$ & $-5.4149 \times 10^{-5}$ & $-1.6306 \times 10^{-5}$ \\
\hline
\end{tabular}

Note: The permissions of reproduction for this T-bar information [6] in Equation (9) and Table 4 are given by Elsevier.

The ULS results obtained by ANSYS FE simulation in Figure $4 \mathrm{~b}$ were directly compared with results obtained by the empirical formulas in Figure 6a-h. In general, the empirical formulation shows relatively good agreement with ANSYS results, based on $\mathrm{R}^{2}$ results. This can also be confirmed by mean and coefficient of variation (COV) values in Table 5 and Figure $7 \mathrm{a}$. When the $\beta$ increased, the ULS tended to have more of a general shape heading to the southeast direction, as shown in Figure 6e-h. In this study, the general shape represented a tendency to regularly decrease diagonally. In particular, this tendency could be observed when the plate was thin. It seems that the buckling of the plate element 
was affecting the overall collapse behaviour of the stiffened panel. As shown in Figure $6 \mathrm{~b}-\mathrm{d}$, when the plate slenderness ratio was less than 1.8, which is generally considered a thick plate, ULS tended to fluctuate greatly, based on the variation of the stiffener size. A good understanding of accuracy was required for each $\beta$ when using the empirical formulation. In particular, this formulation may need a thin plate, having a large value of $\beta$, as shown in Figure $6 \mathrm{e}-\mathrm{h}$.

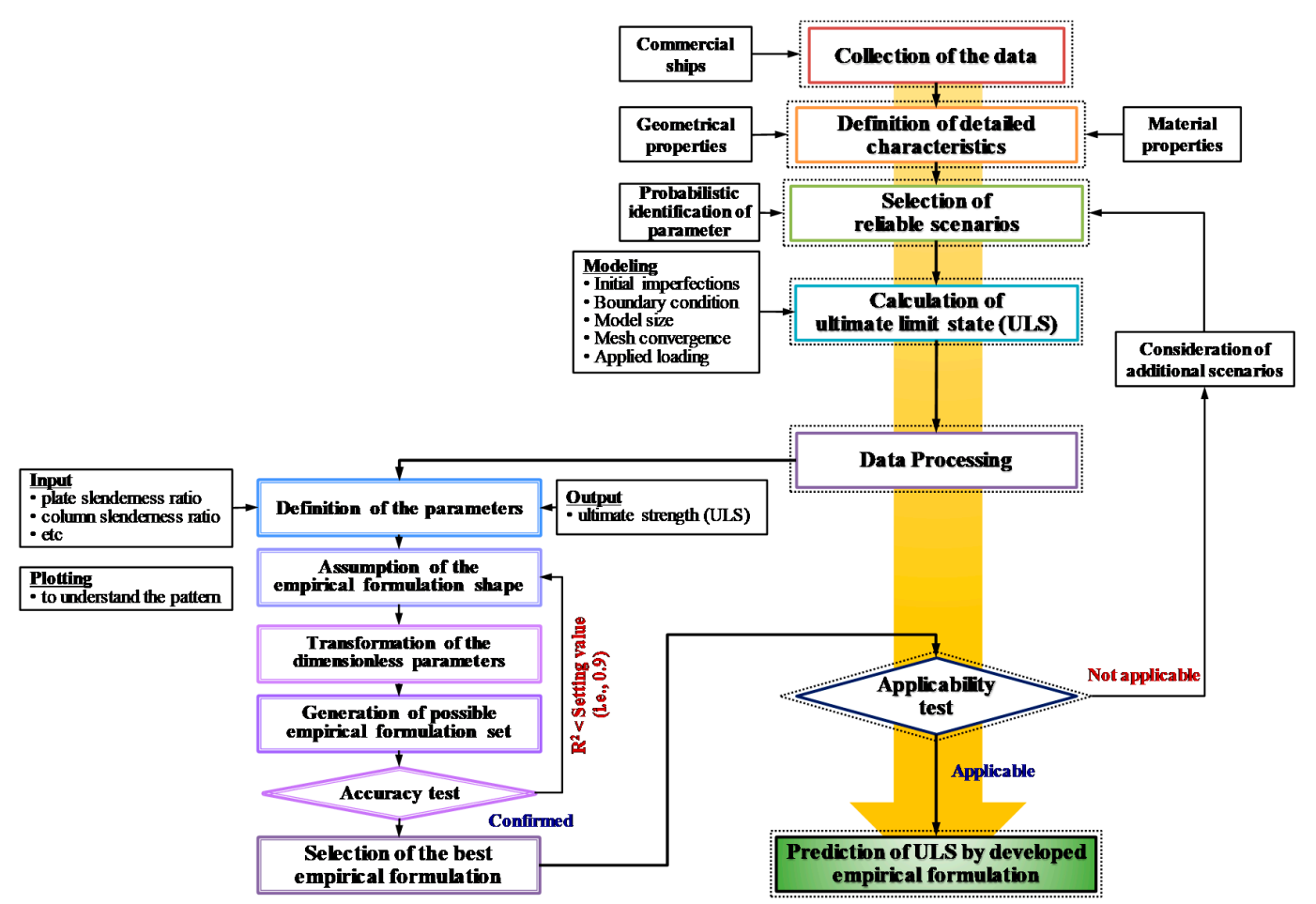

Figure 5. Development of empirical formulation by data processing technique [6]. (Note: The permission of reproduction for this figure is given by Elsevier).

In this study, we verified that the applicability of the empirical formulation in Equation (9) can be extended to flat-bar stiffened panel with a new set of coefficients as summarised in Table 4 . This shows relatively good agreement with ANSYS results, with the maximum and minimum range of the $\mathrm{R}^{2}$ values $\left(0.8881 \leq R^{2} \leq 0.9435\right)$. However, it can be further improved by studying the phenomenon of the flat-bar stiffened panel under longitudinal compression in future. Particularly, the collapse behaviour of the plate under longitudinal compression should be studied. 


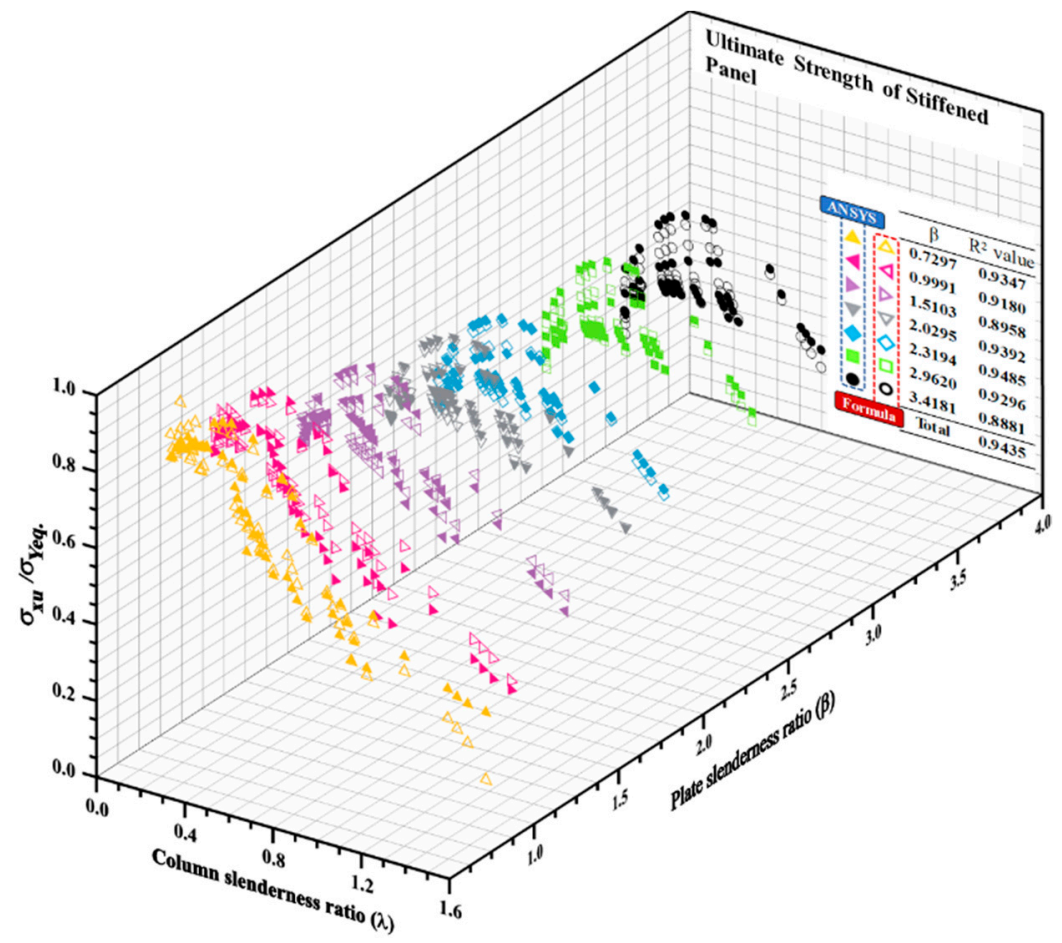

(a) all $\beta$

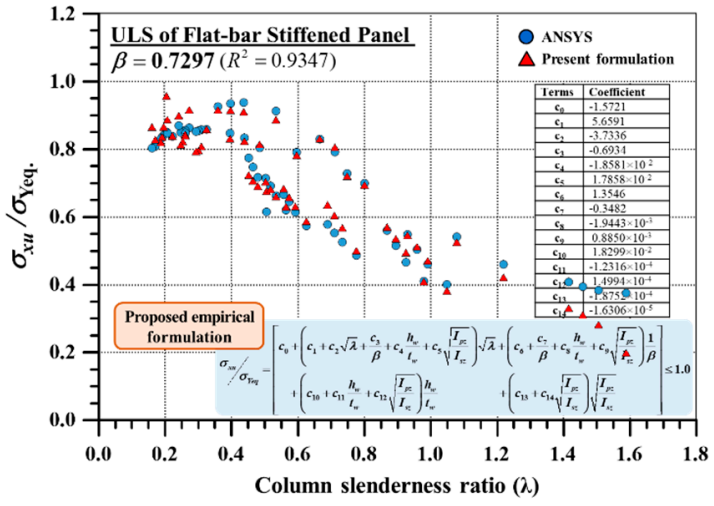

(b) $\beta=0.7297$

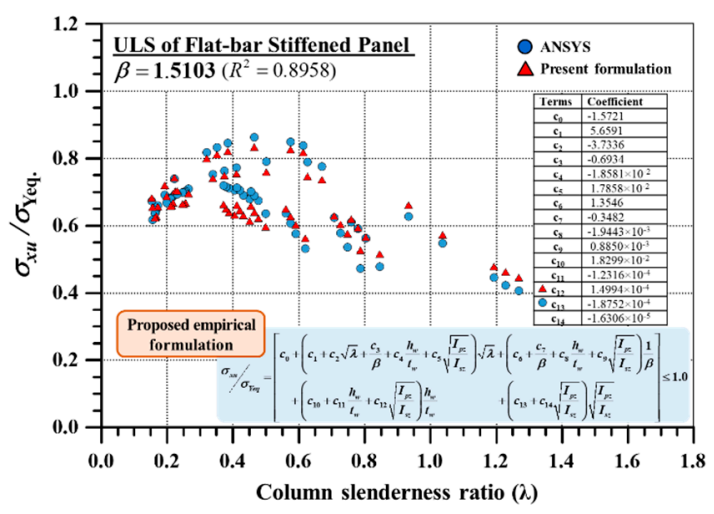

(d) $\beta=1.5103$

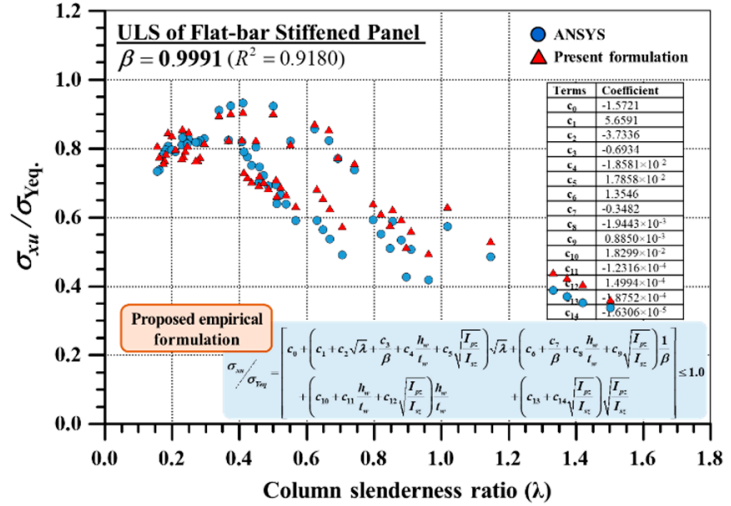

(c) $\beta=0.9991$

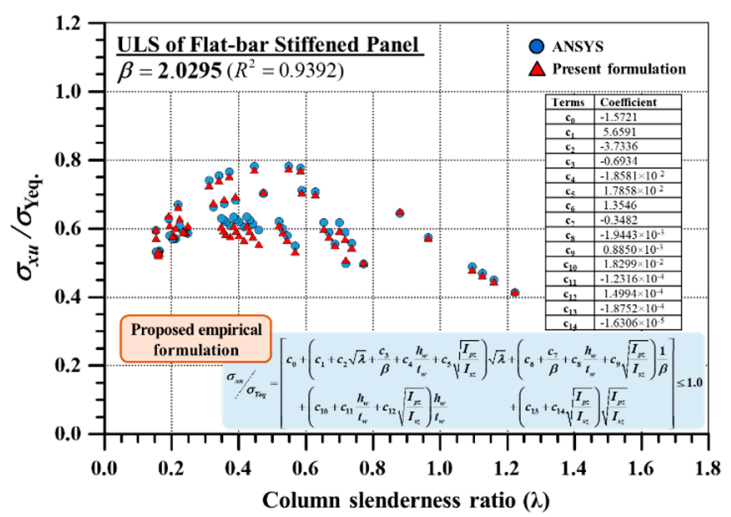

(e) $\beta=2.0295$

Figure 6. Cont. 


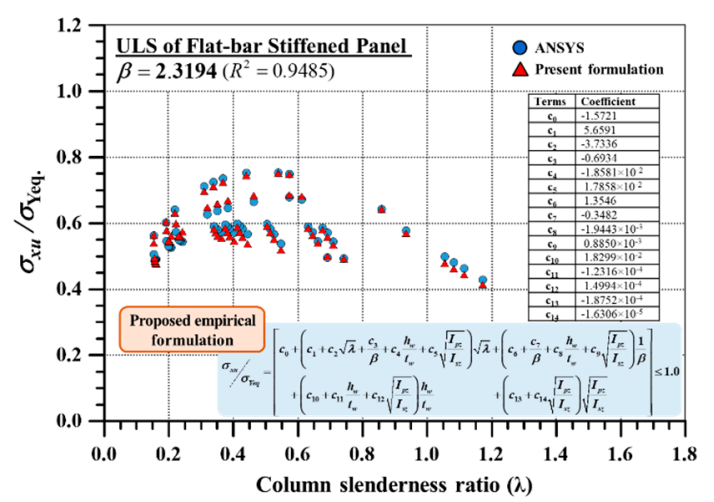

(f) $\beta=2.3194$

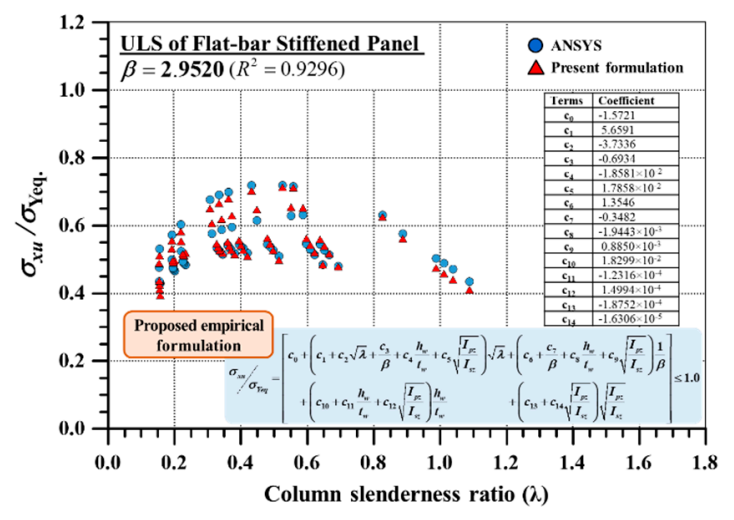

(g) $\beta=2.9520$

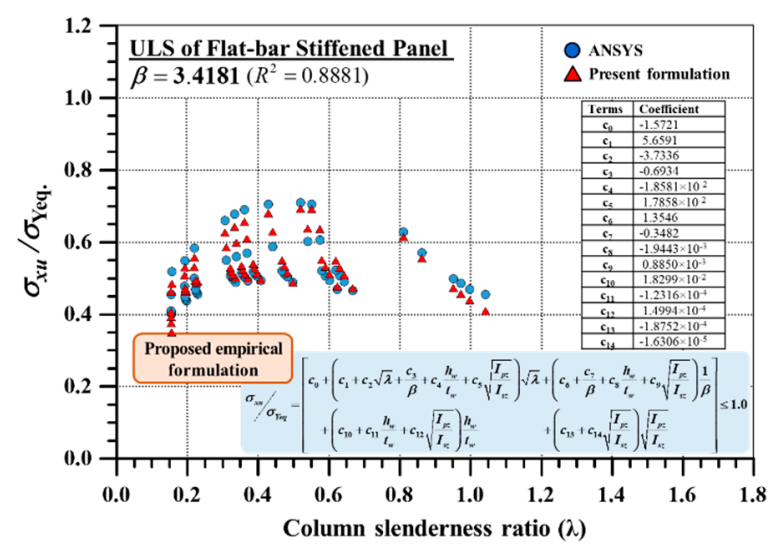

(h) $\beta=3.4181$

Figure 6. ULS comparison between ANSYS and obtained empirical formulation. 
Table 5. Statistical analysis results.

\begin{tabular}{|c|c|c|c|c|c|c|c|c|c|c|c|c|c|c|c|c|c|}
\hline \multirow{3}{*}{\multicolumn{2}{|c|}{ Existing Methods }} & \multicolumn{16}{|c|}{ Plate Slenderness Ratio $(\beta)$} \\
\hline & & \multicolumn{2}{|c|}{0.7297} & \multicolumn{2}{|c|}{0.9991} & \multicolumn{2}{|c|}{1.5103} & \multicolumn{2}{|c|}{2.0295} & \multicolumn{2}{|c|}{2.3194} & \multicolumn{2}{|c|}{2.9520} & \multicolumn{2}{|c|}{3.4181} & \multicolumn{2}{|c|}{ ALL } \\
\hline & & Mean & $\mathrm{COV}$ & Mean & $\mathrm{COV}$ & Mean & $\mathrm{COV}$ & Mean & $\mathrm{COV}$ & Mean & $\mathrm{COV}$ & Mean & $\mathrm{COV}$ & Mean & $\mathrm{COV}$ & Mean & $\mathrm{COV}$ \\
\hline \multirow{3}{*}{$\begin{array}{c}\text { Design } \\
\text { Formulations }\end{array}$} & $\mathrm{J}-\mathrm{O}$ & 1.2958 & 0.1634 & 1.3206 & 0.1453 & 1.3994 & 0.1084 & 1.5453 & 0.1151 & 1.6289 & 0.1267 & 1.7750 & 0.1462 & 1.8591 & 0.1577 & 1.5463 & 0.1932 \\
\hline & P-R & 1.3047 & 0.1777 & 1.3337 & 0.1618 & 1.4122 & 0.1179 & 1.5567 & 0.1136 & 1.6393 & 0.1224 & 1.7825 & 0.1398 & 1.8640 & 0.1511 & 1.5562 & 0.1924 \\
\hline & Euler & 1.4282 & 0.2393 & 1.4344 & 0.2071 & 1.4955 & 0.1327 & 1.6413 & 0.1037 & 1.7277 & 0.1067 & 1.8818 & 0.1212 & 1.9684 & 0.1316 & 1.6539 & 0.1922 \\
\hline \multirow{6}{*}{$\begin{array}{c}\text { Empirical } \\
\text { Formulations }\end{array}$} & Lin & 1.1532 & 0.1314 & 1.1473 & 0.1189 & 1.1349 & 0.1148 & 1.1436 & 0.1383 & 1.1392 & 0.1491 & 1.0939 & 0.1637 & 1.0456 & 0.1723 & 1.1225 & 0.1452 \\
\hline & P-T & 1.2112 & 0.1528 & 1.1933 & 0.1432 & 1.1587 & 0.1161 & 1.1508 & 0.1270 & 1.1415 & 0.1404 & 1.0909 & 0.1621 & 1.0409 & 0.1743 & 1.1410 & 0.1530 \\
\hline & Z-K & 1.2987 & 0.1466 & 1.3149 & 0.1354 & 1.2455 & 0.1047 & 1.2691 & 0.1198 & 1.2899 & 0.1324 & 1.3159 & 0.1517 & 1.3240 & 0.1626 & 1.2938 & 0.1395 \\
\hline & Kim & 1.1448 & 0.1465 & 1.0990 & 0.1353 & 1.0730 & 0.1080 & 1.1186 & 0.1336 & 1.1487 & 0.1493 & 1.1936 & 0.1717 & 1.2150 & 0.1840 & 1.1418 & 0.1562 \\
\hline & $\mathbf{X u}$ & 1.3531 & 0.1767 & 1.3212 & 0.1333 & 1.2891 & 0.1125 & 1.3440 & 0.1253 & 1.3871 & 0.1386 & 1.4839 & 0.1652 & 1.5668 & 0.1824 & 1.3922 & 0.1662 \\
\hline & Present & 0.9857 & 0.0904 & 1.0363 & 0.0712 & 0.9909 & 0.0565 & 0.9886 & 0.0306 & 0.9958 & 0.0299 & 1.0064 & 0.0364 & 1.0128 & 0.0474 & 1.0024 & 0.0583 \\
\hline $\begin{array}{c}\text { Analytical } \\
\text { Solution }\end{array}$ & ALPS/ULSAP & 0.8704 & 0.3479 & 0.9012 & 0.3456 & 0.8965 & 0.3843 & 0.8527 & 0.3963 & 0.7940 & 0.4180 & 0.7342 & 0.4396 & 0.7331 & 0.4618 & 0.8260 & 0.4046 \\
\hline
\end{tabular}

* Johnson and Ostenfeld (J-O); Perry and Robertson (P-R) Lin = Lin (Lin) [25]; Paik and Thayamballi (P-T) [26], Zhang and Khan (Z-K) [28], Kim et al. (Kim) [21], and Xu et al. (Xu) [29]. 


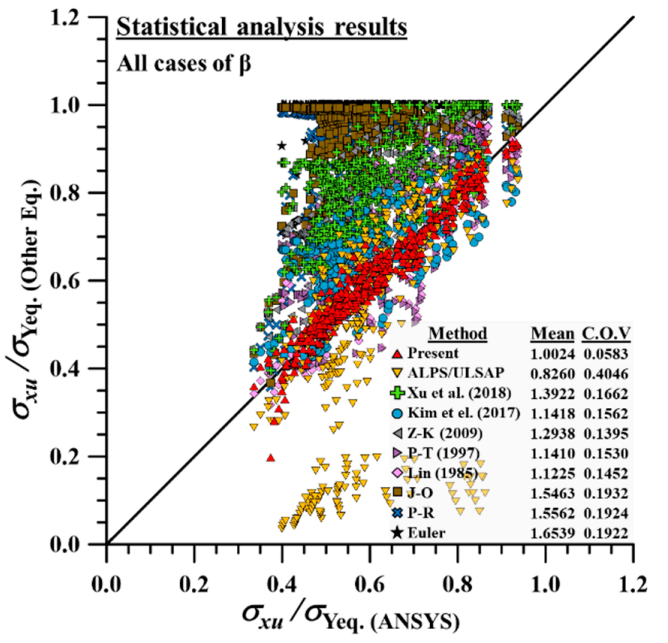

(a) all $\beta$

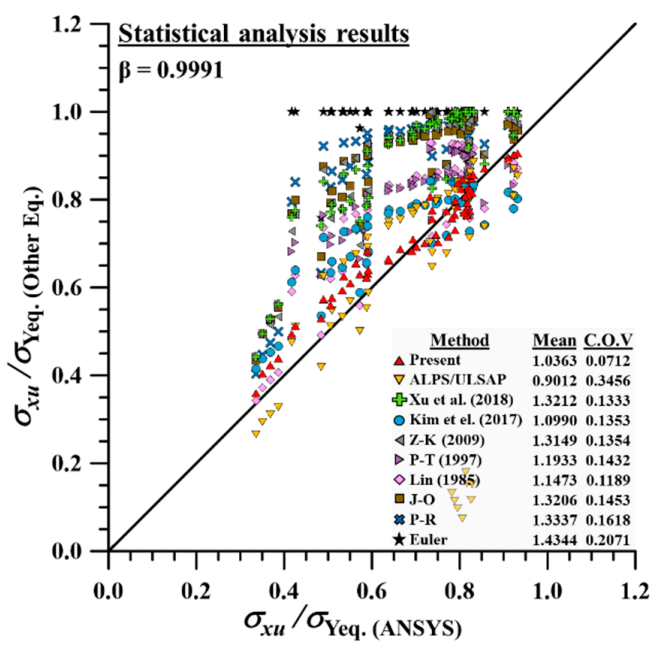

(c) $\beta=0.9991$

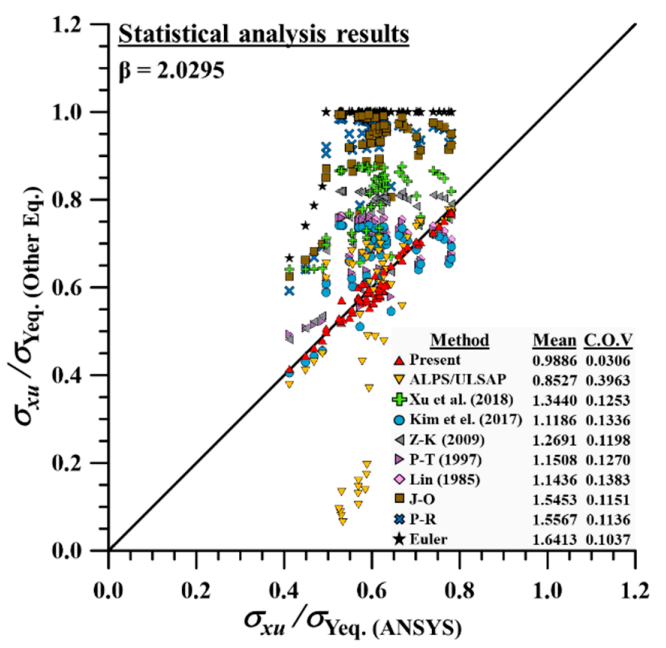

(e) $\beta=2.0295$

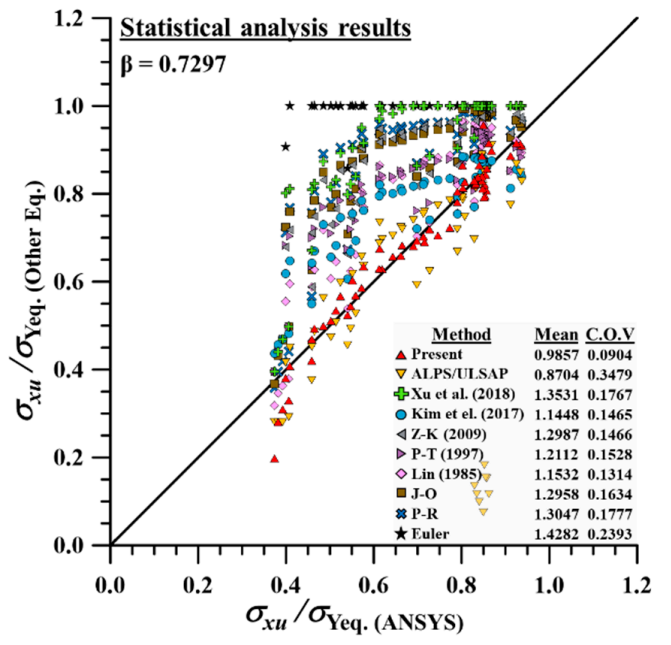

(b) $\beta=0.7297$

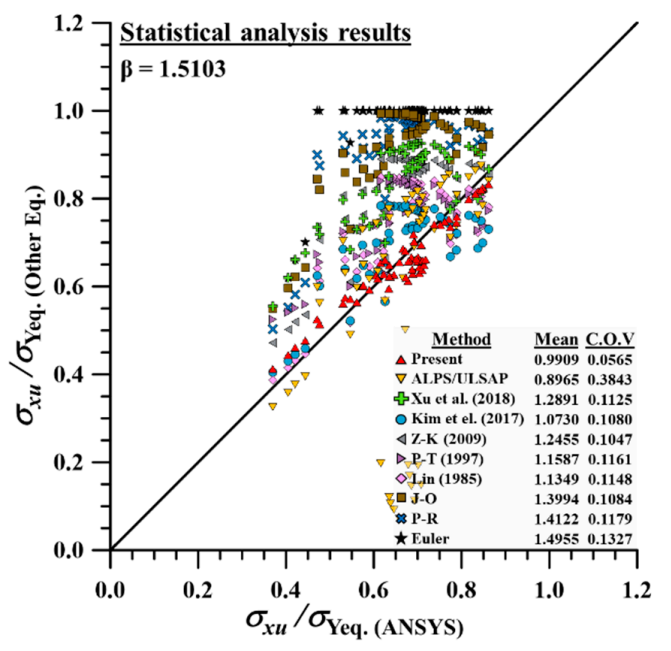

(d) $\beta=1.5103$

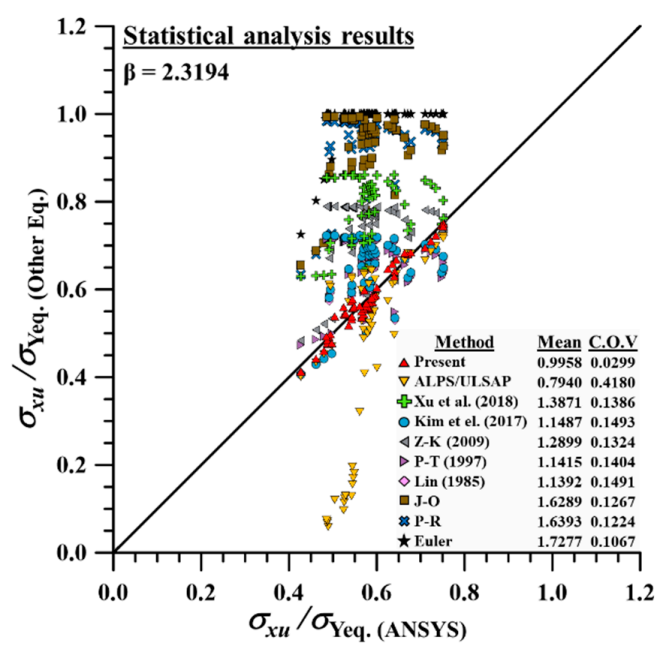

(f) $\beta=2.3194$

Figure 7. Cont. 


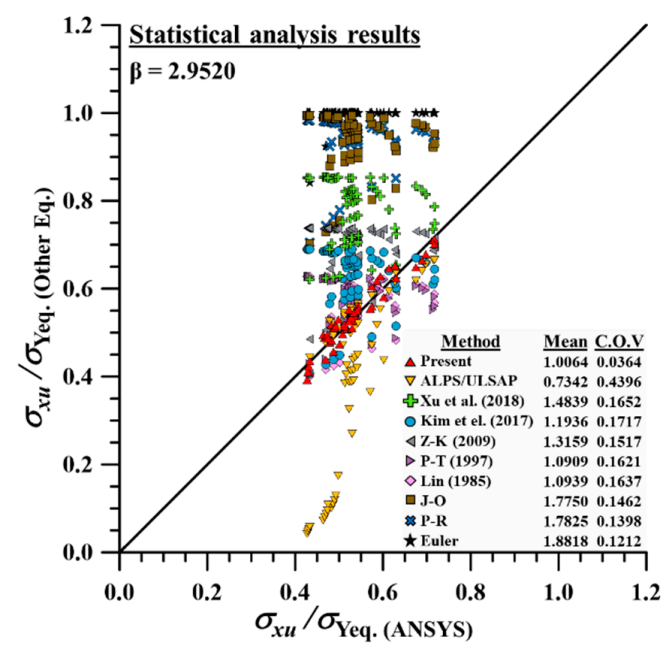

(g) $\beta=2.9520$

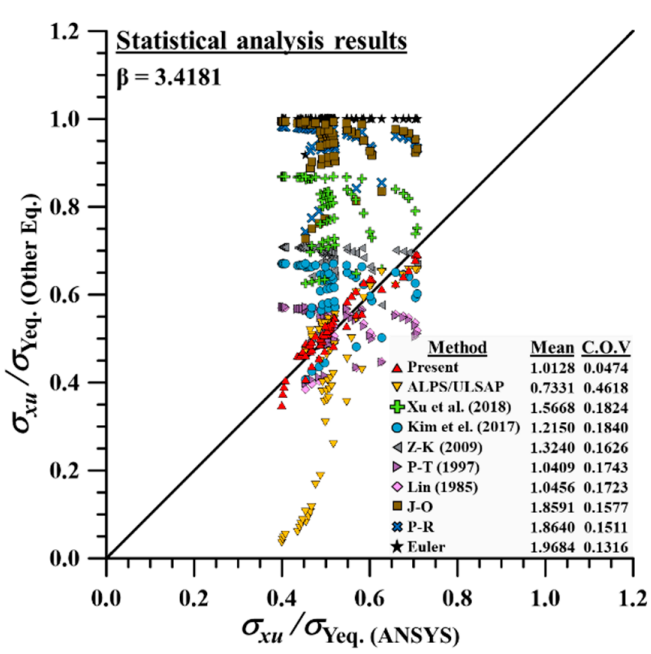

(h) $\beta=3.4181$

Figure 7. Statistical analysis between ANSYS and individual formulations (continued).

\subsection{Statistical Analysis for Verification of Developed Empirical Formulation}

The ULS results obtained by various methods, such as numerical simulations $[55,56]$ and empirical formulations $[21,25,26,28,29]$, together with the proposed refined empirical formulation in this study, as well as ALPS/ULSAP [56], which is a computer program for ultimate limit state assessment for stiffened panel (ULSAP), were plotted in Appendix B and presented in Figure A1a-g. Details on ALPS/ULSAP can be found in Appendix C. In the case of Zhang and Khan [28], they limited it within the range of $\lambda \leq \sqrt{2}$. The detailed comparisons were conducted by statistical analysis, as summarised in Table 5. The statistical analysis results are also represented in Figure 7a-h. As expected, design formulations, such as J-O, P-R, and Euler tended to overestimate the ULS by about $55-65 \%$, compared to the ANSYS FE numerical simulation, referring to the mean value in the "ALL" column shown in Table $5(1.5463 \leq$ mean $\leq 1.6539$ and $0.1922 \leq \mathrm{COV} \leq 0.1932)$.

In the case of the empirical formulations, improved results of mean and COV were observed, compared to design formulations $(1.1225 \leq$ mean $\leq 1.3922$ and $0.1395 \leq \mathrm{COV} \leq 0.1662)$. Most of the existing empirical formulations slightly overestimated the ULS values. On the other hand, ALPS/ULSAP, which is considered am analytical solution, underestimated ULS values by about $17-18 \%$, compared to ANSYS numerical simulation results (mean $=0.8260$ and COV $=0.4046$ ). In particular, severe underestimation was observed when the column slenderness ratio $(\lambda)$ between 0.1 and 0.3 . If this range of $\lambda$ was excluded, this study showed that the mean and COV values were significantly improved to 0.9912 and 0.1389 , respectively. In this study, we selected a reliable but limited range of flat-bar type stiffened panel. The empirical formulation proposed by this study provided well-fitted ULS results with ANSYS FE simulations (mean $=1.0024$ and COV $=0.0583$ ).

In summary, design formulations, which are generally adopted in shipbuilding, overestimate ULS values rather than empirical formulations and analytical solutions (ALPS/ULSAP). Most of the existing empirical formulations show good agreement with the refined FEM results by ANSYS. However, single line shaped empirical formulations still have limitations for predicting the ULS values accurately. The ALPS/ULSAP, which is an analytical method-based solution, can be considered a reliable way to take into account the nonlinearity of the ULS values. However, ALPS/ULSAP is recommended only when the $\lambda$ is greater than 0.3. An additional advantage of ALPS/ULSAP is that it enables robust design through pessimistic analysis results.

Lastly, the proposed empirical formulation in this study considered two more parameters mentioned in Section 4.1, so that it enabled us to predict ULS values and its nonlinearities accurately. 


\subsection{Additional Considerations}

With regards to the effect of material grade on ultimate strength of stiffened panel, Li et al. [57] provided the investigation results using the ABAQUS numerical simulation code by using the arc-length method and allowing large displacement of the structures. They only modelled the single plate-stiffener combination (PSC) model, but the results may be useful for the comparison of different yield strength effects. They adopted the hungry horse mode, based on information by ISSC [58], and considered four steel grades, such as $235,315,355$, and $390 \mathrm{MPa}$, of yield strength. They concluded that increasing the yield strength can effectively improve the ULS of stiffened panels, except for those slender members with large column slenderness ratio. They also mentioned that ULS is dispersed between 0.2 and 0.8 when column slenderness ratio ranges between 0.4 and 0.8 .

Prior to this study, Kim et al. [21] stated this fluctuation behaviour in small column slenderness ratios. $\mathrm{Li}$ et al. [57] also mentioned that the maximum reduction due to welding-induced residual stress effect might be $10 \%$. It was also stated by Khan and Zhang [52] that 10-13\% of ultimate strength decreased due to the effect of compressive residual stress. The detailed investigation on the effect of geometrical imperfections can be found in the research by ISSC [7,54]. With regards to initial imperfection, ISSC [59] conclude that less than $5 \%$ of the ultimate strength may be influenced by ultimate strength.

\section{Conclusions}

In this study, the refined empirical formulation was proposed to predict ultimate strength performance or ultimate limit state (ULS) of flat-bar type steel stiffened panel under longitudinal compression. In total, 420 cases of numerical simulations by the ANSYS non-linear finite element method (NLFEM) were conducted and used as input data to develop an empirical formulation. The formulation obtained showed good agreement with ANSYS results in general $\left(0.8881 \leq R^{2} \leq\right.$ 0.9485), as shown in Table 6. In conclusion, it was verified that the obtained empirical formulation obtained was well fitted with ANSYS numerical simulation results $\left(R^{2}=0.9435\right)$.

Table 6. The obtained $R^{2}$ values from Figure $6 a$.

\begin{tabular}{cc}
\hline Plate Slenderness Ratio $(\boldsymbol{\beta})$ & $\mathbf{R}^{\mathbf{2}}$ \\
\hline 0.7297 & 0.9347 \\
0.9991 & 0.9180 \\
1.5103 & 0.8958 \\
2.0295 & 0.9392 \\
2.3194 & 0.9485 \\
2.9620 & 0.9296 \\
3.4181 & 0.8881 \\
\hline Total & $\mathbf{0 . 9 4 3 5}$ \\
\hline
\end{tabular}

The detailed results are summarised as follows.

\subsection{Findings}

- When the plate slenderness ratio ( $\beta$ ) increased, the ULS tended to be a generalised shape, which represented a tendency to regularly decrease diagonally, as shown in Figure 6e-h. This may have been caused by the buckling of the plate element, which affected the overall collapse behaviour of the stiffened panel. In addition, this trend was observed when the plate was considered thin $(1.8 \leq \beta)$

- As represented in Figure $6 \mathrm{~b}-\mathrm{d}$, when the plate got thick, the ultimate limit state (ULS or ultimate strength) tended to fluctuate greatly depending on the variation of the stiffener size.

- Two parameters, i.e., column slenderness ratio $(\lambda)$ and plate slenderness ratio $(\beta)$, were considered as the main parameters of the existing empirical formulations. As indicated by Kim et al. [21,24], 
single line-shaped existing empirical formulations may not be able to implement the fluctuation behaviour of ULS. This means that the additional parameters should be considered in predicting the accurate ULS in the region of fluctuation.

- The applicability of the refined empirical formulation proposed by Kim et al. [6] was tested by statistical analysis. It was confirmed that proposed empirical formulation can be applied to flat-type stiffened panel with 14 modified coefficients.

The limitations of this study are also documented as follows, of which should be further studied in future:

\subsection{Limitations}

- The empirical formulation proposed by this study was based on the ANSYS numerical simulation results with assumed scenarios in Table 2 and boundary conditions in Table 3b. It is well recognised that data processing depends on the input data. This means that other types of input data, e.g., ULS values obtained by an experimental or analytical method, would provide slightly different final outcomes. Nevertheless, the numerical simulation results assumed by a simply supported boundary condition with average level initial deflection may help designers in the robust design of ships and offshore structures by maintaining the additional structural safety margin.

- This study only considers the prediction of ULS of steel stiffened panel, i.e., a ship's deck or upper side shell stiffened panel under longitudinal compression. Other types of applied loadings, such as biaxial compression and lateral pressure, should also be taken into consideration in future.

- With regard to initial imperfection, initial deflection of plate and initial distortion of stiffener are only considered in this study, while welding-induced residual stress was not considered.

- In addition, other types of stiffener (angle-bar type) should also be studied to develop the empirical formulation.

Author Contributions: Conceptualization, D.K.K.; methodology, D.K.K., S.Y.Y.; software, H.L.L.; validation D.K.K. and H.L.L.; formal analysis, D.K.K., S.Y.Y., H.L.L., and N.-K.C.; investigation, N.-K.C.; writing-original draft preparation, D.K.K. and S.Y.Y.; writing-review and editing, N.-K.C.; All authors have read and agreed to the published version of the manuscript.

Funding: This study was supported by the Research Program funded by the SeoulTech (Seoul National University of Science and Technology.

Acknowledgments: Authors appreciate kind supports from POSTECH (Korea), UTP (Malaysia), and Newcastle University (UK).

Conflicts of Interest: The authors declare no conflict of interest.

\section{Appendix A. Initial Imperfections}

Initial imperfections including initial distortion (initial deflection of plate and initial distortion of stiffener) and welding induced residual stress should be carefully taken into account for the ultimate strength analysis of structures. In this study, we only considered initial distortions.

The three types of initial distortions considered in this study are summarised as follows. In general, it can be categorised as plate initial deflection $\left(w_{\text {opl }}\right)$, the column type initial distortion of the stiffener $\left(w_{o c}\right)$, and the sideways initial distortion of the stiffener $\left(w_{o s}\right)$. In case of plate initial deflection, there are various modes such as hungry horse mode, mountain mode, spoon mode, sinusoidal mode, and buckling mode $[60,61]$. Among them, buckling mode is adopted in this study.

- Buckling mode initial deflection of plate:

$w_{\text {opl }}=A_{o} \sin \left(\frac{m \pi x}{a}\right) \sin \left(\frac{\pi y}{b}\right)$ for plate;

- Column type distortion of stiffener:

$w_{o c}=B_{o} \sin \left(\frac{\pi x}{a}\right) \sin \left(\frac{\pi y}{B}\right)$ for stiffener (Column-type); 
- Sideways initial distortion of stiffener:

$w_{o s}=C_{o} \frac{z}{h_{w}} \sin \left(\frac{\pi x}{a}\right)$ for stiffener (Sideways).

where, $A_{0}, B_{0}$, and $C_{0}=$ coefficients of the initial distortion $\left(0.1 \beta^{2} t, 0.0015 \mathrm{a}\right.$, and 0.0015 respectively $)$, $\mathrm{m}=$ buckling mode of the plate which provides minimum integer satisfying $a / b \leq \sqrt{m(m+1)}$, $a=$ plate length, $b=$ plate breadth, $B=$ breadth of stiffened panel ( 1 bay $-1 \mathrm{span}), h_{w}=$ web height.

\section{Appendix B. Comparison of ULS Results with Existing Methods}

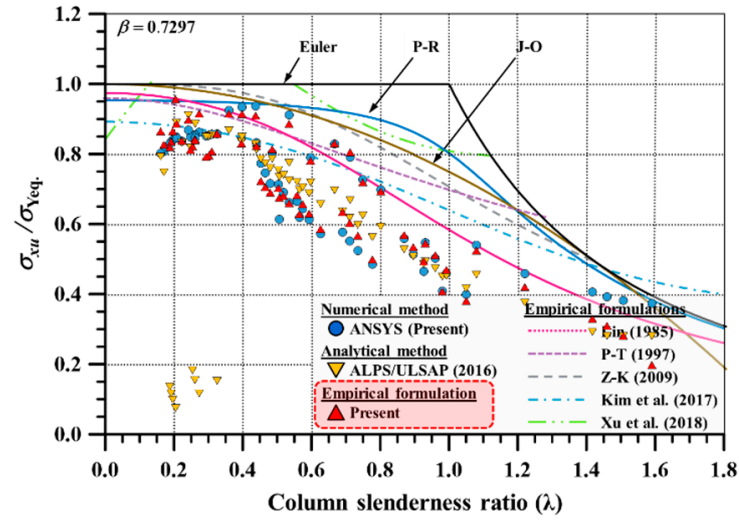

(a) $\beta=0.7297$

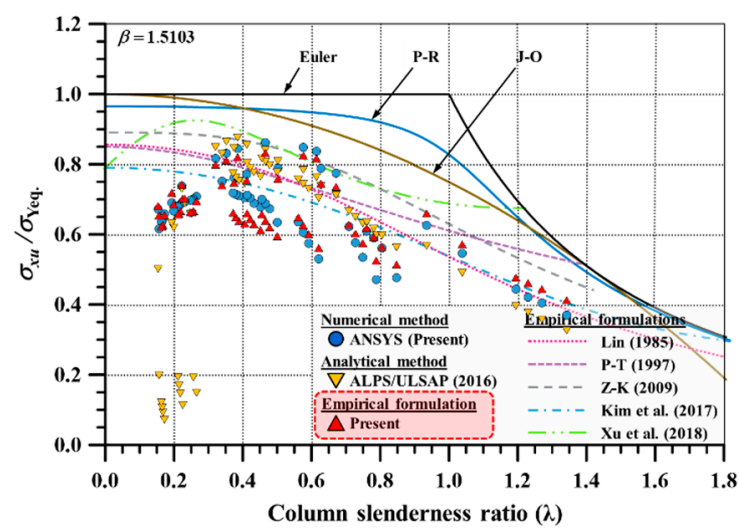

(c) $\beta=1.5103$

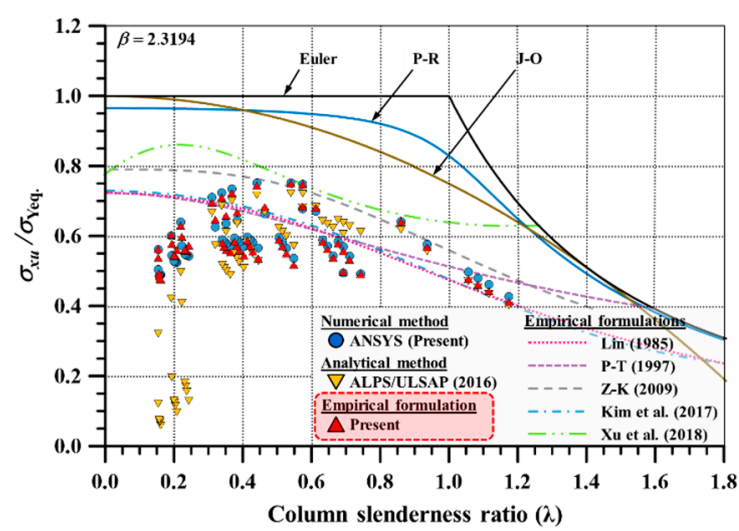

(e) $\beta=2.3194$

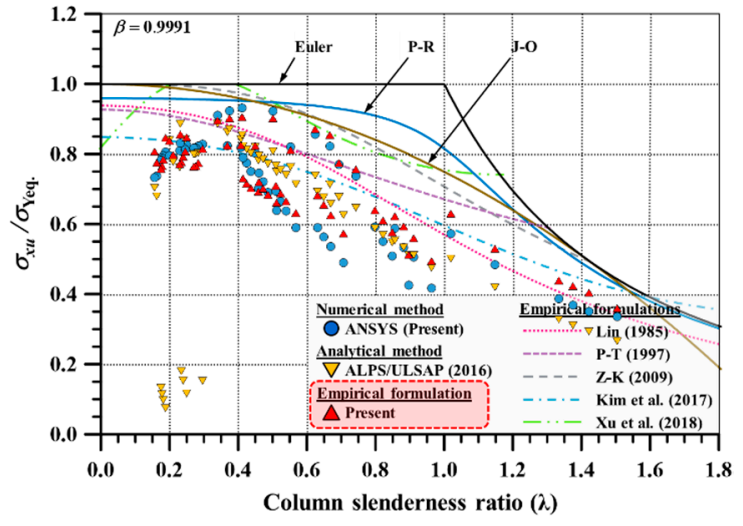

(b) $\beta=0.9991$

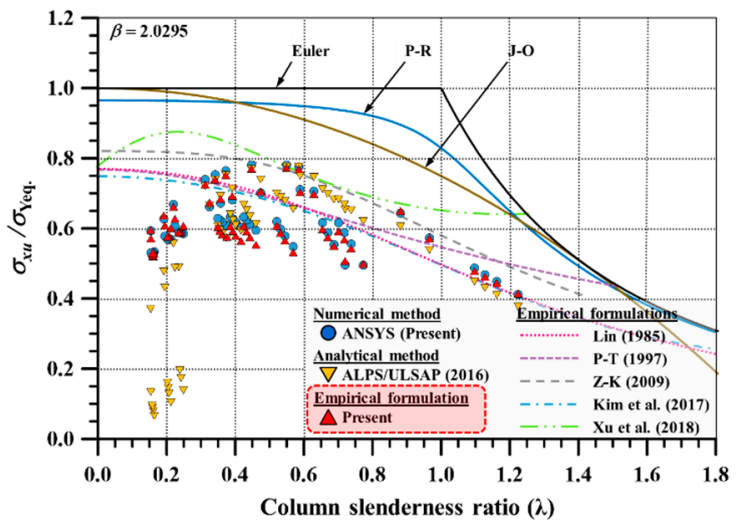

(d) $\beta=2.0295$

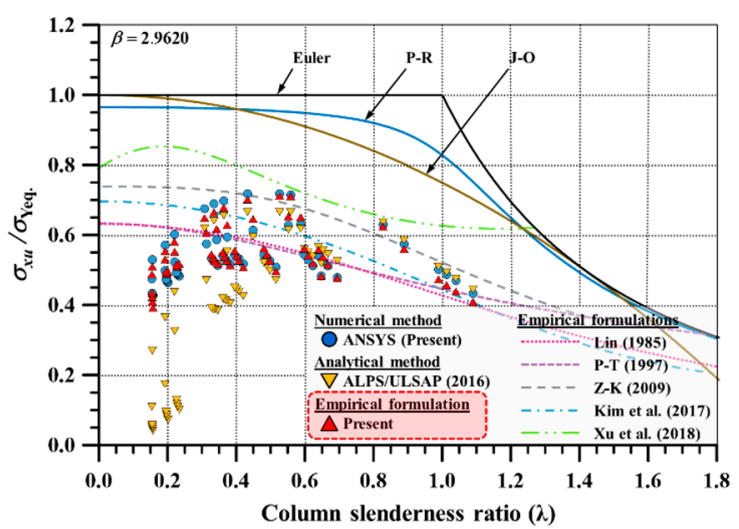

(f) $\beta=2.9520$

Figure A1. Cont. 


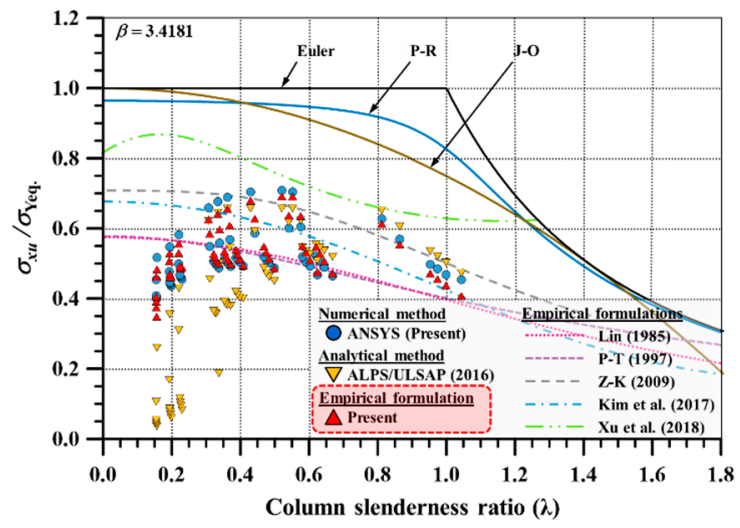

(g) $\beta=3.4181$

Figure A1. Comparison of ULS results.

\section{Appendix C. ALPS/ULSAP Program}

The ALPS/ULSAP program, developed for assessing ultimate limit state of stiffened panel is calculating its ultimate strength based on assumed six (6) types of collapse modes as shown in Figure A2. Once the ultimate strength values for six different modes are calculated, the lowest ultimate strength value will then be selected as ULS of stiffened panel. In this regards, ALPS/ULSAP gives relatively lower value of ultimate strength than other methods but it provides additional safe margins. This ALPS/ULSAP results are also presented in Figure A1a-g.

In this study, stiffener-induced collapse by beam-column type collapse (collapse mode 3) and stiffener-induced collapse by web buckling (mode 4) were observed from the most of the scenarios while overall collapse mode (mode 1) is also detected in typical scenario.

Details may be found in the ISSC [7] report, as well as by following references $[60,62,63]$. In addition, ALPS/ULSAP program is also available using MAESTRO modeller together with ALPS/HULL program [63].
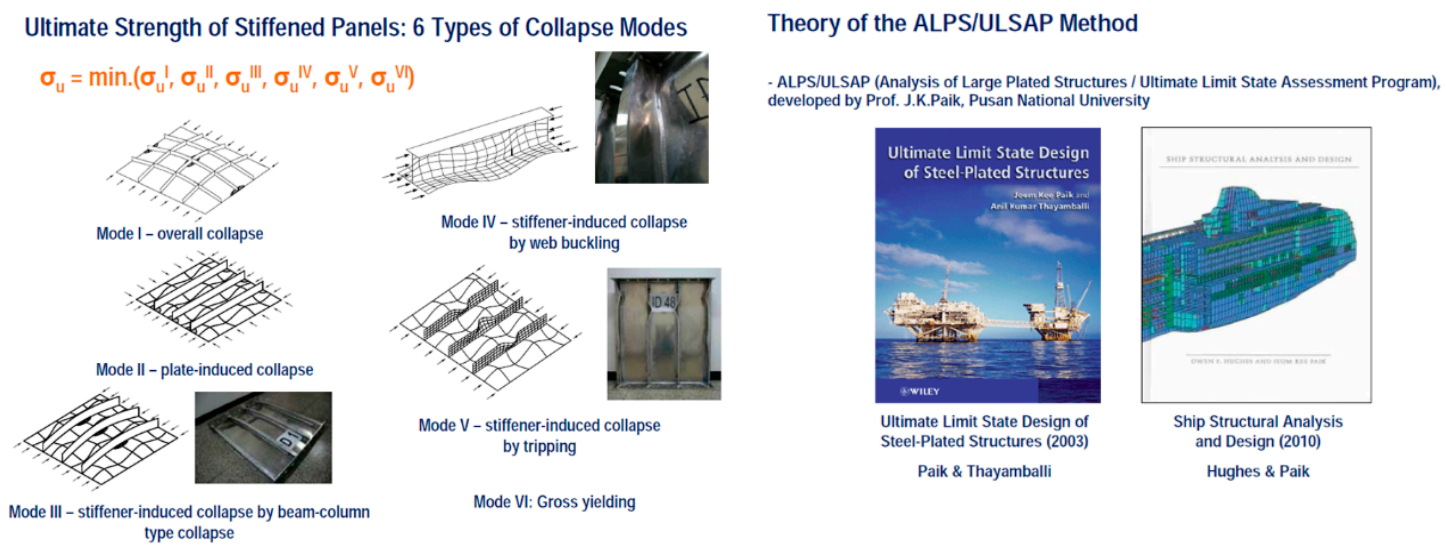

Figure A2. ALPS/ULSAP method and assumed collapse mode for ULS calculation, ALPS = nonlinear Analysis of Large Plated Structures; ULSAP = Ultimate Limit State Assessment of stiffened Panel) [64].

\section{References}

1. Park, D.K.; Paik, J.K.; Kim, B.J.; Seo, J.K.; Li, C.G.; Kim, D.K. Ultimate strength performance of Northern Sea going non-ice class commercial ships. Struct. Eng. Mech. 2014, 52, 613-632. [CrossRef]

2. Park, D.K.; Kim, D.K.; Park, C.H.; Park, D.H.; Jang, B.S.; Kim, B.J.; Paik, J.K. On the crashworthiness of steel-plated structures in an arctic environment: An experimental and numerical study. J. Offshore Mech. Arct. Eng. 2015, 137, 051501. [CrossRef] 
3. Park, D.K.; Kim, D.K.; Seo, J.K.; Kim, B.J.; Ha, Y.C.; Paik, J.K. Operability of non-ice class aged ships in the Arctic Ocean-Part II: Accidental limit state approach. Ocean Eng. 2015, 102, 206-215. [CrossRef]

4. Topa, A.; Kim, D.K.; Kim, Y.T. 3D Numerical simulation of seamless pipe piercing process by fluid-structure interaction method. MATEC Web Conf. 2018, 203, 06016. [CrossRef]

5. Paik, J.K. Advanced Structural Safety Studies with Extreme Conditions and Accidents; Springer: Singapore, 2020. [CrossRef]

6. Kim, D.K.; Lim, H.L.; Yu, S.Y. Ultimate strength prediction of T-bar stiffened panel under longitudinal compression by data processing: A refined empirical formulation. Ocean Eng. 2019, 192, 106522. [CrossRef]

7. ISSC. Ultimate Strength (Committee III.1). In Proceedings of the 18th International Ship and Offshore Structures Congress (ISSC 2012), Rostock, Germany, 9-13 September 2012.

8. Paik, J.K.; Kim, D.K.; Park, D.H.; Kim, H.B.; Mansour, A.E.; Caldwell, J.B. Modified Paik-Mansour formula for ultimate strength calculations of ship hulls. Ships Offshore Struct. 2013, 8, 245-260. [CrossRef]

9. Paik, J.K.; Kim, D.K.; Park, D.H.; Kim, H.B.; Kim, M.S. A new method for assessing the safety of ships damaged by grounding. Int. J. Marit. Eng. 2012, 154, T2012-1.

10. Kim, D.K.; Pedersen, P.T.; Paik, J.K.; Kim, H.B.; Zhang, X.M.; Kim, M.S. Safety guidelines of ultimate hull girder strength for grounded container ships. Saf. Sci. 2013, 59, 46-54. [CrossRef]

11. Kim, D.K.; Kim, H.B.; Mohd, M.H.; Paik, J.K. Comparison of residual strength—Grounding damage index diagrams for tankers produced by the ALPS/HULL ISFEM and design formula method. Int. J. Nav. Archit. Ocean Eng. 2013, 5, 47-61. [CrossRef]

12. Kim, D.K.; Kim, B.J.; Seo, J.K.; Kim, H.B.; Zhang, X.M.; Paik, J.K. Time-dependent corrosion damage on the development of residual strength-Grounding damage index diagram. Ocean Eng. 2014, 76, 163-171. [CrossRef]

13. Zhang, S.; Pedersen, P.T.; Villavicencio, R. Probability and Mechanics of Ship Collision and Grounding; Elsevier Inc.: Oxford, UK, 2019. [CrossRef]

14. Kim, D.K.; Kim, H.B.; Park, D.H.; Mohd, M.H.; Paik, J.K. A practical diagram to determine the residual longitudinal strength of grounded ship in Northern Sea Route. Ships Offshore Struct. 2020, 15, 683-700. [CrossRef]

15. Paik, J.K.; Kim, B.J.; Seo, J.K. Methods for ultimate limit state assessment of ships and ship-shaped offshore structures: Part I Unstiffened plates. Ocean Eng. 2008, 35, 261-270. [CrossRef]

16. Paik, J.K. Ultimate Limit State Analysis and Design of Plated Structures, 2nd ed.; John Wiley \& Sons: Chichester, UK, 2018.

17. Kim, D.K.; Poh, B.Y.; Lee, J.R.; Paik, J.K. Ultimate strength of initially deflected plate under longitudinal compression: Part I = An advanced empirical formulation. Struct. Eng. Mech. 2018, 68, 247-259.

18. Tanaka, Y.; Endo, H. Ultimate strength of stiffened plates with their stiffeners locally buckled in compression. J. Soc. Nav. Archit. Jpn. 1988, 164, 456-467. [CrossRef]

19. Tanaka, S.; Yanagihara, D.; Yasuoka, A.; Harada, M.; Okazawa, S.; Fujikubo, M.; Yao, T. Evaluation of ultimate strength of stiffened panels under longitudinal thrust. Mar. Struct. 2014, 36, 21-50. [CrossRef]

20. Liew, A.; Gardner, L. Ultimate capacity of structural steel cross-sections under compression, bending and combined loading. Structures 2015, 1, 2-11. [CrossRef]

21. Kim, D.K.; Lim, H.L.; Kim, M.S.; Hwang, O.J.; Park, K.S. An empirical formulation for predicting the ultimate strength of stiffened panels subjected to longitudinal compression. Ocean Eng. 2017, 140, 270-280. [CrossRef]

22. Ozdemir, M.; Ergin, A.; Yanagihara, D.; Tanaka, S.; Yao, T. A new method to estimate ultimate strength of stiffened panels under longitudinal thrust based on analytical formulas. Mar. Struct. 2018, 59, 510-535. [CrossRef]

23. Zhang, S.M. A review and study on ultimate strength of steel plates and stiffened panels in axial compression. Ships Offshore Struct. 2016, 11, 81-91. [CrossRef]

24. Kim, D.K.; Lim, H.L.; Yu, S.Y. A technical review on ultimate strength prediction of stiffened panels in axial compression. Ocean Eng. 2018, 170, 392-406. [CrossRef]

25. Lin, Y.T. Structural Longitudinal Strength Modelling. Ph.D. Dissertation, University of Glasgow, Glasgow, UK, 1985.

26. Paik, J.K.; Thayamballi, A.K. An Empirical Formulation for Predicting the Ultimate Compressive Strength of Stiffened Panels. In Proceedings of the 7th International Offshore and Polar Engineering Conference (ISOPE 1997), Honolulu, HI, USA, 25-30 May 1997. ISOPE-I-97-444. 
27. Paik, J.K. Empirical formulations for predicting the ultimate compressive strength of welded aluminum stiffened panels. Thin Walled Struct. 2007, 45, 171-184. [CrossRef]

28. Zhang, S.M.; Khan, I. Buckling and ultimate capability of plates and stiffened panels in axial compression. Mar. Struct. 2009, 22, 791-808. [CrossRef]

29. Xu, M.C.; Song, Z.J.; Zhang, B.W.; Pan, J. Empirical formula for predicting ultimate strength of stiffened panel of ship structure under combined longitudinal compression and lateral loads. Ocean Eng. 2018, 162, 161-175. [CrossRef]

30. Khedmati, M.R.; Zareei, M.R.; Rigo, P. Empirical formulations for estimation of ultimate strength of continuous stiffened aluminium plates under combined in-plane compression and lateral pressure. Thin Walled Struct. 2010, 48, 274-289. [CrossRef]

31. Mei, H.; Wang, D. An Empirical Formula for Predicting Elastic Ultimate Buckling Strength of Flat-Bar Stiffened Panels with Initial Imperfections. In Proceedings of the 38th International Conference on Ocean, Offshore and Arctic Engineering (OMAE 2019), Glasgow, UK, 9-14 June 2019.

32. IACS. Common Structural Rules for Bulk Carriers and Oil Tankers; International Association of Classification Societies: London, UK, 2017; Available online: www.iacs.org.uk/media/3922/csr-h-01-jan-2017.pdf (accessed on 1 January 2019).

33. IACS. Common Structural Rules for Double Hull Oil Tankers; International Association of Classification Societies: London, UK, 2006.

34. IACS. Common Structural Rules for Bulk Carriers; International Association of Classification Societies: London, UK, 2006.

35. Jiameng, W.; Gang, W.; Shijian, C. Ramification Study on IACS Harmonized Common Structural Rules: Impact on Structural Design and Scantlings; SNAME Maritime Convention (SMC): Houston, TX, USA, 20-25 October 2014.

36. Anyfantis, K.N. Ultimate strength of stiffened panels subjected to non-uniform thrust. Int. J. Nav. Archit. Ocean Eng. 2020, 12, 325-342. [CrossRef]

37. Silva, H.M.; Wojewoda, J. Determination of the product of inertia of stiffened plates based on Finite Element Method results. Eng. Struct. 2020, 207, 110201. [CrossRef]

38. Shi, G.J.; Gao, D.W. Transverse ultimate capacity of U-type stiffened panels for hatch covers used in ship cargo holds. Ships Offshore Struct.. in press. [CrossRef]

39. Kong, X.; Yang, Y.; Gan, J.; Yuan, Y.; Ao, L.; Wu, W. Experimental and numerical investigation on the detailed buckling process of similar stiffened panels subjected to in-plane compressive load. Thin Walled Struct. 2020, 148, 106620. [CrossRef]

40. Wang, Q.; Wang, D. Scaling characteristics of hull girder's ultimate strength and failure behaviors: An empirically modified scaling criterion. Ocean Eng. 2020, 212, 107595. [CrossRef]

41. Song, Z.J.; Xu, M.C.; Moan, T.; Pan, J. Dimensional and similitude analysis of stiffened panels under longitudinal compression considering buckling behaviours. Ocean Eng. 2019, 187, 106188. [CrossRef]

42. Liu, B.; Garbatov, Y.; Wu, W.; Soares, C.G. Strength assessment of aluminium and steel stiffened panels with openings on longitudinal girders. Ocean Eng. 2020, 200, 107047.

43. Jagite, G.; Bigot, F.; Derbanne, Q.; Malenica, Š.; Le Sourne, H.; Cartraud, P. A parametric study on the dynamic ultimate strength of a stiffened panel subjected to wave- and whipping-induced stresses. Ships Offshore Struct.. in press. [CrossRef]

44. Ahmadi, F.; Ranji, A.R.; Nowruzi, H. Ultimate strength prediction of corroded plates with center-longitudinal crack using FEM and ANN. Ocean Eng. 2020, 206, 107281. [CrossRef]

45. Wong, E.W.C.; Kim, D.K. A simplified method to predict fatigue damage of TTR subjected to short-term VIV using Artificial Neural Network. Adv. Eng. Softw. 2018, 126, 100-109. [CrossRef]

46. Kim, D.K.; Incecik, A.; Choi, H.S.; Wong, E.W.C.; Yu, S.Y.; Park, K.S. A simplified method to predict fatigue damage of offshore riser subjected to vortex-induced vibration by adopting current index concept. Ocean Eng. 2018, 157, 401-411. [CrossRef]

47. Park, D.K.; Kim, D.K.; Seo, J.K.; Kim, B.J.; Ha, Y.C.; Paik, J.K. Operability of non-ice class aged ships in the Arctic Ocean-Part I: Ultimate limit state approach. Ocean Eng. 2015, 102, 197-205. [CrossRef]

48. Choi, H.S.; Seo, D.W.; Kim, K.H.; Shin, G.; Choung, J.M.; Kim, K.S.; Wong, E.W.C.; Topa, A.; Kim, D.K. Applicability of high manganese steel to FLNG storage tank considering collision event. J. Mar. Sci. Eng.. under review. 
49. Choi, H.S.; Shin, G.; Choung, J.M.; Kim, K.H.; Seo, D.W.; Kim, K.S.; Wong, E.W.C.; Kim, D.K. Numerical Simulation of High Manganese Steel FLNG Storage Tank Damaged by Collision. In Proceedings of the 3rd International Conference on Ocean, Mechanical and Aerospace for Scientist and Engineer (OMAse 2016), Kuala Terengganu, Malaysia, 7-8 November 2016.

50. Paik, J.K.; Kim, D.K.; Lee, H.; Shim, Y.L. A method for analyzing elastic large deflection behavior of perfect and imperfect plates with partially rotation-restrained edges. J. Offshore Mech. Arct. Eng. 2012, 134, 021603. [CrossRef]

51. Ahmer Wadee, M.; Farsi, M. Imperfection sensitivity and geometric effects in stiffened plates susceptible to cellular buckling. Structures 2015, 3, 172-186. [CrossRef]

52. Khan, I.; Zhang, S. Effects of welding-induced residual stress on ultimate strength of plates and stiffened panels. Ships Offshore Struct. 2011, 6, 297-309. [CrossRef]

53. De Queiroz, J.P.T.; Cunha, M.L.; Pavlovic, A.; Rocha, L.A.O.; dos Santos, E.D.; Troina, G.D.S.; Isoldi, L.A. Geometric evaluation of stiffened steel plates subjected to transverse loading for naval and offshore applications. J. Mar. Sci. Eng. 2019, 7, 7. [CrossRef]

54. ISSC. Ultimate Strength (Committee III.1). In Proceedings of the 17th International Ship and Offshore Structures Congress (ISSC 2009), Seoul, Korea, 16-21 August 2009.

55. ANSYS. User's Manual Version 13.0; ANSYS Inc.: Canonsburg, PA, USA, 2014.

56. ALPS/ULSAP. A Computer Program for Ultimate Limit State Assessment of Stiffened Panels; Advanced Technology Center, DRS C3 Systems: Parsippany, NJ, USA, 2016; Available online: www.maestromarine.com (accessed on 1 January 2019).

57. Li, C.; Dong, S.; Wang, T.; Xu, W.; Zhou, X. Numerical investigation on ultimate compressive strength of welded stiffened plates built by steel grades of S235-S390. Appl. Sci. 2019, 9, 2088. [CrossRef]

58. ISSC. Ultimate Hull Girder Strength (Special Committee VI.2). In Proceedings of the 14th International Ship and Offshore Structures Congress (ISSC 2015), Nagasaki, Japan, 2-6 October 2000.

59. ISSC. Ultimate Strength (Committee III.1). In Proceedings of the 19th International Ship and Offshore Structures Congress (ISSC 2015), Cascais, Portugal, 7-10 September 2015.

60. Paik, J.K.; Thayamballi, A.K. Ultimate Limit State Design of Steel-Plated Structures; John Wiley \& Sons: Chichester, UK, 2003.

61. Kim, D.K.; Park, D.K.; Kim, J.H.; Kim, S.J.; Kim, B.J.; Seo, J.K.; Paik, J.K. Effect of corrosion on the ultimate strength of double hull oil tankers—Part I: Stiffened panels. Struct. Eng. Mech. 2012, 42, 507-530. [CrossRef]

62. Hughes, O.F.; Paik, J.K. Ship Structural Analysis and Design; The Society of Naval Architects and Marine Engineers: Jersey City, NJ, USA, 2010.

63. MAESTRO. FEA for the Naval Architect. Available online: https://www.maestromarine.com (accessed on 1 January 2019).

64. Paik, J.K. Ultimate Strength of Plates and Stiffened Panels; The LRET Research Collegium, University of Southampton: Southampton, UK, 11 July-2 September 2011; Available online: https:/cdn.southampton.ac.uk/assets/imported/transforms/content-block/UsefulDownloads_ Download/FC5BD932BC234B728195E4FE96F0D831/alecture14\%20paik2.pdf (accessed on 1 January 2019).

(C) 2020 by the authors. Licensee MDPI, Basel, Switzerland. This article is an open access article distributed under the terms and conditions of the Creative Commons Attribution (CC BY) license (http://creativecommons.org/licenses/by/4.0/). 